\title{
A local glucose-and oxygen concentration-based insulin secretion model for pancreatic islets
}

Peter Buchwald

\author{
Correspondence: pbuchwald@med. \\ miami.edu \\ Diabetes Research Institute and the \\ Department of Molecular and \\ Cellular Pharmacology, University \\ of Miami, Miller School of \\ Medicine, Miami, FL, USA
}

\begin{abstract}
Background: Because insulin is the main regulator of glucose homeostasis, quantitative models describing the dynamics of glucose-induced insulin secretion are of obvious interest. Here, a computational model is introduced that focuses not on organism-level concentrations, but on the quantitative modeling of local, cellularlevel glucose-insulin dynamics by incorporating the detailed spatial distribution of the concentrations of interest within isolated avascular pancreatic islets.

Methods: All nutrient consumption and hormone release rates were assumed to follow Hill-type sigmoid dependences on local concentrations. Insulin secretion rates depend on both the glucose concentration and its time-gradient, resulting in second-and first-phase responses, respectively. Since hypoxia may also be an important limiting factor in avascular islets, oxygen and cell viability considerations were also built in by incorporating and extending our previous islet cell oxygen consumption model. A finite element method (FEM) framework is used to combine reactive rates with mass transport by convection and diffusion as well as fluidmechanics.
\end{abstract}

Results: The model was calibrated using experimental results from dynamic glucosestimulated insulin release (GSIR) perifusion studies with isolated islets. Further optimization is still needed, but calculated insulin responses to stepwise increments in the incoming glucose concentration are in good agreement with existing experimental insulin release data characterizing glucose and oxygen dependence. The model makes possible the detailed description of the intraislet spatial distributions of insulin, glucose, and oxygen levels. In agreement with recent observations, modeling also suggests that smaller islets perform better when transplanted and/or encapsulated.

Conclusions: An insulin secretion model was implemented by coupling local consumption and release rates to calculations of the spatial distributions of all species of interest. The resulting glucose-insulin control system fits in the general framework of a sigmoid proportional-integral-derivative controller, a generalized PID controller, more suitable for biological systems, which are always nonlinear due to the maximum response being limited. Because of the general framework of the implementation, simulations can be carried out for arbitrary geometries including cultured, perifused, transplanted, and encapsulated islets.

Keywords: diabetes mellitus, FEM model, glucose-insulin dynamics, Hill equation, islet perifusion, islets of Langerhans, oxygen consumption, PID controller 


\section{Background}

In healthy humans, blood glucose levels have to be maintained in a relatively narrow range: typically $4-5 \mathrm{mM}$ and usually within $3.5-7.0 \mathrm{mM}(60-125 \mathrm{mg} / \mathrm{dL})$ in fasting subjects $[1,2]$. This is mainly achieved via the finely-tuned glucose-insulin control system whereby $\beta$-cells located in pancreatic islets act as glucose sensors and adjust their insulin output as a function of the blood glucose level. Pancreatic islets are structurally well-defined spheroidal cell aggregates of about one to two thousand hormone-secreting endocrine cells ( $\alpha, \beta, \gamma$, and PP-cells). Human islets have diameters ranging up to about $500 \mu \mathrm{m}$ with a size distribution that is well described by a Weibull distribution function, and islets with diameters of $100-150 \mu \mathrm{m}$ are the most representative [3]. Because abnormalities in $\beta$-cell function are the main culprit behind elevated glucose levels, quantitative models describing the dynamics of glucose-stimulated insulin release (GSIR) are of obvious interest [1] for both type 1 (insulin-dependent or juvenile-onset) and type 2 (non-insulin dependent or adult-onset) diabetes mellitus. They could help not only to better understand the process, but also to more accurately assess $\beta$-cell function and insulin resistance. Abnormalities in $\beta$-cell function are critical in defining the risk and development of type 2 diabetes [4], a rapidly increasing therapeutic burden in industrialized nations due to the increasing prevalence of obesity $[5,6]$. A quantitative understanding of how healthy $\beta$-cells maintain normal glucose levels is also of critical importance for the development of 'artificial pancreas' systems [7] including automated closed-loop insulin delivery systems [8-10] as well as for the development of 'bioartificial pancreas' systems such as those using immune-isolated, encapsulated islets [11-13]. Accordingly, mathematical models have been developed to describe the glucose-insulin regulatory system using organism-level concentrations, and they are widely used, for example, to estimate glucose effectiveness and insulin sensitivity from intravenous glucose tolerance tests (IVGTT). They include curve-fitting models such as the "minimal model" [14] and many others [15-17] as well as paradigm models such as HOMA $[18,19]$. There is also considerable interest in models focusing on insulin release from encapsulated islets [20-26], an approach that is being explored as a possibility to immunoisolate and protect transplanted islets.

The goal of the present work is to develop a finite element method (FEM)-based model that (1) focuses not on organism-level concentrations, but on the quantitative modeling of local, cellular-level glucose-insulin dynamics by incorporating the detailed spatial distribution of the concentrations of interest and that (2) was calibrated by fitting experimental results from dynamic GSIR perifusion studies with isolated islets. Such perifusion studies allow the quantitative assessment of insulin release kinetics under fully controllable experimental conditions of varying external concentrations of glucose, oxygen, or other compounds of interest [27-30], and are now routinely used to assess islet quality and function. Microfluidic chip technologies make now possible even the quantitative monitoring of single islet insulin secretion with high time-resolution [31]. We focused on the modeling of such data because they are better suited for a first-step modeling than those of insulin release studies of fully vascularized islets in live organism, which are difficult to obtain accurately and are also influenced by many other factors. Lack of vasculature in the isolated islets considered here might cause some delay in the response compared with normal islets in their natural environment; however, the diffusion time $\left(L^{2} / D\right)$ [32] to (or from) the middle of a 'standard' islet (d 
$=150 \mu \mathrm{m}$ ) is roughly of the order of only $10 \mathrm{~s}$ for glucose and $100 \mathrm{~s}$ for insulin (with the diffusion coefficients used here)-relatively small delays. Furthermore, because of the spherical structure, most of the cell mass is located in the outer regions of the islets (i.e., about $70 \%$ within the outer third of the radius) further diminishing the roles of these delays.

By using a general approach that couples local (i.e., cellular level) hormone release and nutrient consumption rates with mass transport by convection and diffusion, the present approach allows implementation for arbitrary 2D or even 3D geometries including those with flowing fluid phases. Hence, the detailed spatial distribution of insulin release, hypoxia, and cell survival can be modeled within a unified framework for cultured, transplanted, encapsulated, or GSIR-perifused pancreatic islets. While there has been considerable work on modeling insulin secretion, no models that couple both convective and diffusive transport with reactive rates for arbitrary geometries have been published yet. Most published models incorporating mass transport focused on encapsulated islets for a bioartificial pancreas [20-26]. Only very few [21,24] included flow, and even those had to assume cylindrical symmetry. Furthermore, the present model also incorporates a comprehensive approach to account not only for first-and second-phase insulin response, but also for both the glucose-and the oxygen-dependence of insulin release. Because the lack of oxygen (hypoxia) due to oxygen diffusion limitations in avascular islets can be an important limiting [33] factor especially in cultured, encapsulated, and freshly transplanted islets [27,28,34,35], it was important to also incorporate this aspect of the glucose-insulin response in the model.

In response to a stepwise increase of glucose, normal, functioning islets release insulin in a biphasic manner: a relatively quick first phase consisting of a transient spike of 5-10 min is followed by a sustained second phase that is slower and somewhat delayed [36-39]. The effect of hypoxic conditions on the insulin release of perifused islets has been studied by a number of groups $[27,28,34,35]$, and they seem to indicate that insulin release decreases nonlinearly with decreasing oxygen availability; however, only relatively few detailed concentration-dependence studies are available. Parametrization of the insulin release model here has been done to fit experimental insulin release data mainly from two studies with the most detailed concentration dependence data available: by Henquin and co-workers for glucose dependence [40] and by Dionne, Colton and co-workers for oxygen dependence [27].

In the present model, the insulin-secreting $\beta$-cells were assumed to act as sensors of both the local glucose concentration and its change (Figure 1). Insulin is released within the islets following Hill-type sigmoid response functions of the local (i.e., cellular level) glucose concentration, $c_{\text {gluc }}$, as well as its time-gradient, $\partial c_{\text {gluc }} / \partial t$, resulting in second-and first-phase insulin responses, respectively. Oxygen and glucose consumption by the islet cells were also incorporated in the model using Michaelis-Mententype kinetics (Hill equation with $n_{\mathrm{H}}=1$ ). Since lack of oxygen (hypoxia) can be important in avascular islets [33], oxygen concentrations were allowed to limit the rate of insulin secretion using again a Hill-type equation. Finally, all the local (cellular-level) oxygen, glucose, and insulin concentrations were tied together with solute transfer equations to calculate observable, external concentrations as a function of time and incoming glucose and oxygen concentrations. 


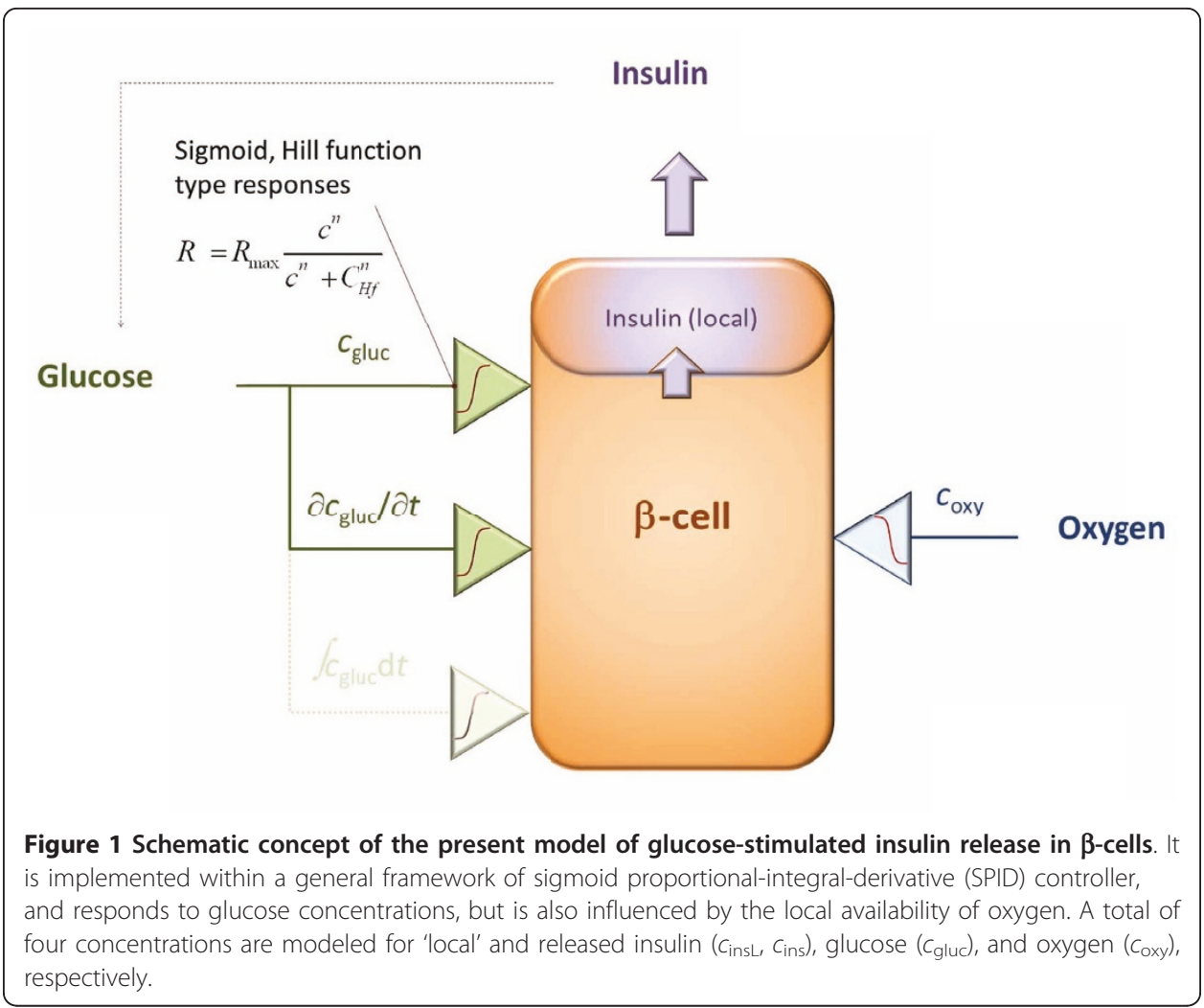

\section{Methods}

\section{Mass transport model (convective and diffusive)}

For a fully comprehensive description, a total of four concentrations were used each with their corresponding equation (application mode) for 'local' and released insulin, glucose, and oxygen, respectively $\left(c_{\text {insL }}, c_{\text {ins }}, c_{\text {gluc }}\right.$, and $\left.c_{\text {oxy }}\right)$. Accordingly, for each of them, diffusion was assumed to be governed by the generic diffusion equation in its nonconservative formulation (incompressible fluid) [32,41]:

$$
\frac{\partial c}{\partial t}+\nabla \cdot(-D \nabla c)=R-\mathbf{u} \cdot \nabla c
$$

where, $c$ denotes the concentration $\left[\mathrm{mol} \mathrm{m}^{-3}\right]$ and $D$ the diffusion coefficient $\left[\mathrm{m}^{2} \mathrm{~s}^{-1}\right]$ of the species of interest, $R$ the reaction rate $\left[\mathrm{mol} \mathrm{m}^{-3} \mathrm{~s}^{-1}\right], \mathbf{u}$ the velocity field $\left[\mathrm{m} \mathrm{s}^{-1}\right]$, and $\nabla$ the standard $\operatorname{del}$ (nabla) operator, $\nabla=\mathbf{i} \frac{\partial}{\partial x}+\mathbf{j} \frac{\partial}{\partial y}+\mathbf{k} \frac{\partial}{\partial z}$ [42]. The following diffusion coefficients were used as consensus estimates of values available from the literature: oxygen, $D_{\text {oxy,w }}=3.0 \times 10^{-9} \mathrm{~m}^{2} \mathrm{~s}^{-1}$ in aqueous media and $D_{\text {oxy, }}=2.0 \times 10^{-9} \mathrm{~m}^{2} \mathrm{~s}^{-}$ ${ }^{1}$ in islet tissue ([33] and references therein); glucose, $D_{\text {gluc,w }}=0.9 \times 10^{-9} \mathrm{~m}^{2} \mathrm{~s}^{-1}$ and $D_{\text {gluc, } \mathrm{t}}=0.3 \times 10^{-9} \mathrm{~m}^{2} \mathrm{~s}^{-1}$; insulin, $D_{\text {ins, } \mathrm{w}}=0.15 \times 10^{-9} \mathrm{~m}^{2} \mathrm{~s}^{-1}$ and $D_{\text {ins, }}=0.05 \times 10^{-9}$ $\mathrm{m}^{2} \mathrm{~s}^{-1}[23,24]$. Published tissue values for glucose vary over a wide range (0.04-0.5 $\times$ $\left.10^{-9} \mathrm{~m}^{2} \mathrm{~s}^{-1}\right)$ [32,43-46]; a value toward the higher end of this range $\left(0.3 \times 10^{-9} \mathrm{~m}^{2} \mathrm{~s}^{-1}\right)$ was used here. Very few tissue values for insulin are available (and the existence of dimers and hexamers only complicates the situation) [32,47]; the value used here was lowered compared to water in a manner similar to glucose. For the case of 
encapsulated islets, the following diffusion coefficients were used for the capsule (e.g., hydrogel matrices such as alginate): $D_{\text {oxy,c }}=2.5 \times 10^{-9} \mathrm{~m}^{2} \mathrm{~s}^{-1}, D_{\text {gluc }, \mathrm{c}}=0.6 \times 10^{-9} \mathrm{~m}^{2} \mathrm{~s}^{-}$ ${ }^{1}, D_{\text {ins }, \mathrm{c}}=0.1 \times 10^{-9} \mathrm{~m}^{2} \mathrm{~s}^{-1}[23,48]$.

\section{Consumption and release rates}

All consumption and release rates were assumed to follow Hill-type dependence on the local concentrations (generalized Michaelis-Menten kinetics):

$$
R=f_{H}(c)=R_{\max } \frac{c^{n}}{c^{n}+C_{H f}^{n}}
$$

The three parameters of this function are $R_{\max }$, the maximum reaction rate $\left[\mathrm{mol} \mathrm{m}{ }^{-3}\right.$ $\left.\mathrm{s}^{-1}\right], C_{\mathrm{Hf}}$, the concentration corresponding to half-maximal response $\left[\mathrm{mol} \mathrm{m}^{-3}\right]$, and $n$, the Hill slope characterizing the shape of the response. This function introduced by A. V. Hill $[49,50]$ provides a convenient mathematical function for biological/pharmacological applications [51]: it allows transition from zero to a limited maximum rate via a smooth, continuously derivable function of adjustable width. Mathematically, the wellknown two-parameter Michaelis-Menten equation [52] represents a special case ( $n=$ 1) of the Hill equation, and eq. 2 also shows analogy with the logistic equation, one of the most widely used sigmoid functional forms, being equivalent with a logarithmic logistic function, $y=f(x)=R_{\max } /\left(1+\beta e^{-n \ln x}\right)$. Obviously, different parameter values are used for the different release and consumption functions (i.e., insulin, glucose, oxygen; e.g., $C_{\mathrm{Hf}, \text { gluc }}, C_{\mathrm{Hf}, \text { oxy }}$, etc.).

\section{Oxygen consumption and cell viability}

For oxygen consumption, the basic values used in our previous model $[33,53]$ were maintained ( $n_{\text {oxy }}=1, R_{\max , \text { oxy }}=-0.034 \mathrm{~mol} \mathrm{~m}^{-3} \mathrm{~s}^{-1}, C_{\mathrm{Hf}, \text { oxy }}=1 \mu \mathrm{M}$-corresponding to a partial oxygen pressure of $p_{\mathrm{Hf}, \mathrm{oxy}}=0.7 \mathrm{mmHg}$ ) since, by all indications, the assumption of a regular Michaelis-Menten kinetics (i.e., $n_{\mathrm{oxy}}=1$ ) gives an adequate fit $[54,55]$. Accordingly, at very low oxygen concentrations, where cells only try to survive, oxygen consumption scales with the available concentration $c_{\text {oxy }}$ and, at sufficiently high concentration, it plateaus at a maximum $\left(R_{\max }\right)$. As before [33], to account for the increased metabolic demand of insulin release and production at higher glucose concentrations, a dependence of $R_{\text {oxy }}$ on the local glucose concentration was also introduced via a modulating function $\phi_{o, g}\left(c_{\text {gluc }}\right)$ :

$$
R_{o x y}=R_{\max , o x y} \frac{c_{o x y}}{c_{o x y}+C_{H f, o x y}} \cdot \varphi_{o, g}\left(c_{g l u c}\right) \cdot \delta\left(c_{o x y}>C_{c r, o x y}\right)
$$

A number of experiments have shown increased oxygen consumption rate in islets when going from low to high glucose concentrations [56-58]. Here, in a slight update of our previous model [33], we assumed that the oxygen consumption rate contains a base-rate and an additional component that increases due to the increasing metabolic demand in parallel with the insulin secretion rate (cf. eq. 6) as a function of the glucose concentration:

$$
\varphi_{o, g}\left(c_{g l u c}\right)=\phi_{s c}\left(\varphi_{\text {base }}+\varphi_{\text {metab }} \frac{c_{\text {gluc }}^{n_{\text {ins } 2 \text { gluc }}}}{c_{\text {gluc }}^{n_{\text {ins } 2, \text { gluc }}}+C_{H f, \text { ins } 2, \text { gluc }}^{n_{\text {ins }} \text {,lluc }}}\right)
$$


Lacking detailed data, as a first estimate, we assumed the base rate to represent $50 \%$ of the total rate possible $\left(\phi_{\text {base }}=\phi_{\text {metab }}=0.5\right)$. To maintain the previously used consumption rate at low $(3 \mathrm{mM})$ glucose, a scaling factor is used, $\Phi_{\mathrm{sc}}=1.8$. The metabolic component fully parallels that used for insulin secretion $\left(n_{\text {ins2,gluc }}=2.5, C_{\mathrm{Hf} \text {,ins2, gluc }}=7\right.$ $\mathrm{mM}$; see eq. 6 later). With this selection, oxygen consumption increases about $70 \%$ when going from low $(3 \mathrm{mM})$ to high glucose $(15 \mathrm{mM})$-slightly less than used previously in our preliminary model [33], but in good agreement with the approximately $50 \%-100 \%$ fold increase seen in various experimental settings [35,36,56-60]. As before [33], a step-down function, $\delta$, was also added to account for necrosis and cut the oxygen consumption of those tissues where the oxygen concentration $c_{\text {oxy }}$ falls below a critical value, $C_{\mathrm{cr}, \text { oxy }}=0.1 \mu \mathrm{M}$ (corresponding to $p_{\mathrm{cr}, \mathrm{xxy}}=0.07 \mathrm{mmHg}$ ). To avoid computational problems due to abrupt transitions, COMSOL's smoothed Heaviside function with a continuous first derivative and without overshoot flc1hs [61] was used as step-down function, $\delta\left(c_{\text {oxy }}>C_{\text {cr,oxy }}\right)=\operatorname{flc} 1 \mathrm{hs}\left(c_{\text {oxy }}-1.0 \times 10^{-4}, 0.5 \times 10^{-4}\right)$.

\section{Glucose consumption}

Glucose consumption, in a manner very similar to oxygen consumption, was assumed to also follow simple Michaelis-Menten kinetics $\left(n_{\text {gluc }}=1\right)$ with $R_{\max , \text { gluc }}=-0.028 \mathrm{~mol}$ $\mathrm{m}^{-3} \mathrm{~s}^{-1}$ and $C_{\mathrm{Hf} \text {,gluc }}=10 \mu \mathrm{M}[23,24,46]$ :

$$
R_{\text {gluc }}=R_{\max , \text { gluc }} \frac{c_{\text {gluc }}}{c_{\text {gluc }}+C_{H f, g l u c}}
$$

These parameter values are draft first estimates only; however, changes in glucose concentrations due to glucose consumption by islets have only minimal influence on insulin release or cell survival because oxygen diffusion limitations in tissue or in media are far more severe than for glucose $[55,62]$. Even if oxygen is consumed at approximately the same rate as glucose on a molar basis and has a 3-4-fold higher diffusion coefficient (i.e., $D_{\mathrm{w}} \mathrm{s}$ used here of $3.0 \times 10^{-9}$ vs. $0.9 \times 10^{-9} \mathrm{~m}^{2} \mathrm{~s}^{-1}$ ), this is more than offset by the differences in the concentrations available under physiological conditions. The solubility of oxygen in culture media or in tissue is much lower than that of glucose; hence, the available oxygen concentrations are much more limited (e.g., around $0.05-0.2 \mathrm{mM}$ vs. 3-15 $\mathrm{mM}$ assuming physiologically relevant conditions) [62]. Glucose consumption by islet cells alters the glucose levels reaching the glucose-sensing $\beta$-cells only minimally.

\section{Insulin release}

Obviously, the most crucial part of the present model is the functional form describing the glucose-(and oxygen) dependence of the insulin secretion rate, $R_{\text {ins }}$. Glucose (or oxygen) is not a substrate per se for insulin production; hence, there is no direct justification for the use of Michaelis-Menten-type enzyme kinetics. Nevertheless, the corresponding generalized form (Hill equation, eq. 2) provides a mathematically convenient functionality that fits well the experimental results. A Hill function with $n>1$ is needed because glucose-insulin response is clearly more abrupt than the rectangular hyperbola of the Michaelis-Menten equation corresponding to $n=1$ as clearly illustrated by the sigmoid-type curve of Figure 2 and by other similar data from various sources $[36,40,63,64]$. In fact, such a function has been used as early as 1972 by Grodsky ( $n=3.3, C_{\mathrm{Hf}, \text { ins,gluc }}=8.3 \mathrm{mM}$; isolated rat pancreas) and justified as resulting from insulin release from individual packets with normally distributed sensitivity 


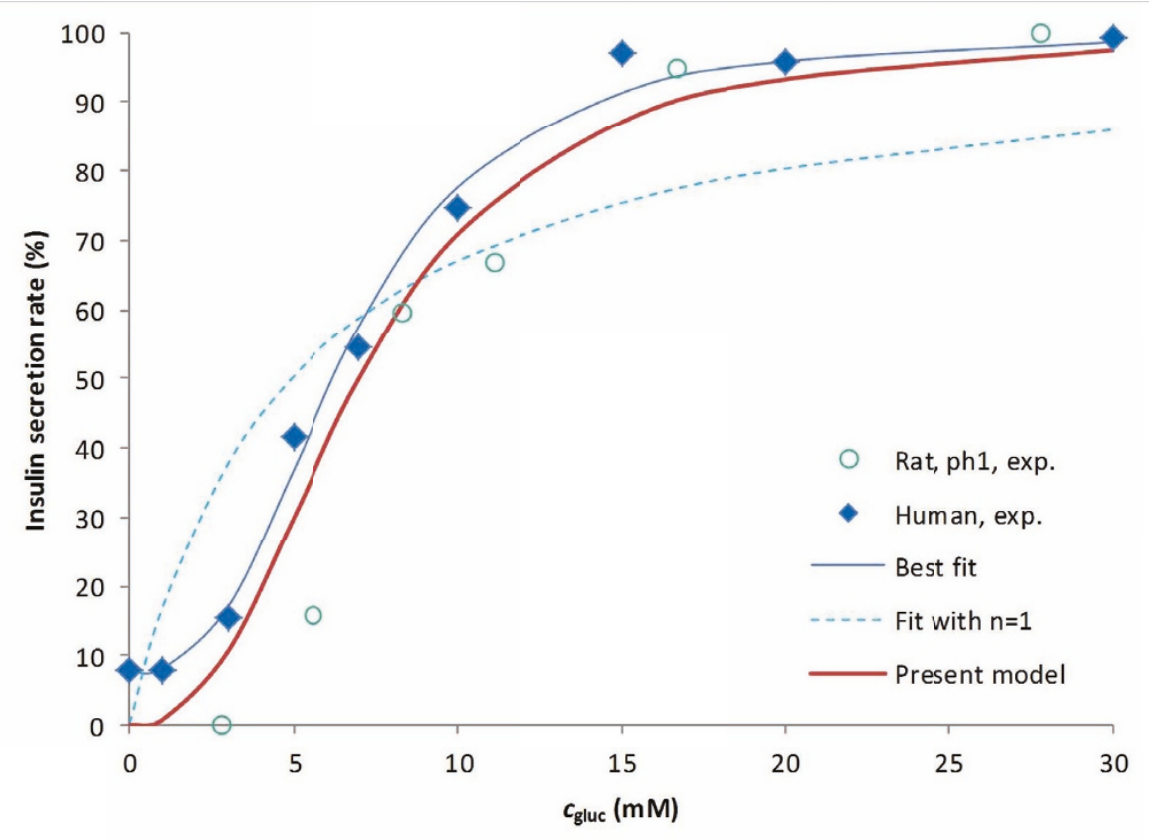

Figure 2 Glucose-dependence of insulin secretion rate in perifused islets. Experimental data are for perifused human islets (blue diamonds) [40] and isolated rat pancreas (blue circles) [63]. Fit of the human data with general Hill-type equations (eq. 2) is shown without any restrictions (best fit, $n=2.7, C_{\text {Hf,gluc }}=$ $6.6 \mathrm{mM}$; blue line), with restricting the Hill slope to unity ( $n=1$, Michaelis-Menten-type function, $C_{\mathrm{Hf} \text {,gluc }}=$ $4.9 \mathrm{mM}$; dashed blue line), and with the present model used for the local concentration (eq. 6) $(n=2.5$, $\mathrm{C}_{\mathrm{Hf}, \mathrm{gluc}}=7 \mathrm{mM}$; red line).

thresholds [63]. However, except for some recent work by Pedersen, Cobelli and coworkers $[65,66]$, such a sigmoid functional dependence has been mostly neglected since then, and most models $[21,23,24]$ used flatter $(n=1)$ response functions combined with exponentially decreasing time-functions. To have a model that can be used for arbitrary incoming glucose profiles, the use of explicit time dependency was avoided here; however, use of an additional 'local' insulin compartment with first order release kinetics (see later) achieves a similar effect. A sufficiently abrupt sigmoid response function on $c_{\text {gluc }}$ ensures an upper limit (plateau) at high glucose concentrations as well as essentially no response at low concentrations (Figure 2) eliminating the need for a specified minimum threshold for effect.

Accordingly, the main function used here to describe the glucose-insulin dynamics of the second-phase response is:

$$
R_{\text {ins, ph2 }}=R_{\max , \text { ins } 2} \frac{c_{\text {gluc }}^{n_{\text {ins } 2 \text { gluc }}}}{c_{\text {gluc }}^{n_{\text {ins } 2, \text { gluc }}}+C_{H f, \text { ins2, gluc }}^{n_{\text {inns } 2 \text { gluc }}}}
$$

with $n_{\text {ins2,gluc }}=2.5, C_{\mathrm{Hf} \text {,ins2,gluc }}=7 \mathrm{mM}$, and $R_{\text {max,ins } 2}=3.0 \times 10^{-5} \mathrm{~mol} \mathrm{~m}^{-3} \mathrm{~s}^{-1}$. These values were obtained here by calculating the predicted insulin output in response to a stepwise increase in incoming glucose and adjusting $n_{\text {ins2,gluc }}$ and $C_{\mathrm{Hf} \text {,ins2,gluc }}$ to obtain best fit with the human islet data of Henquin and co-workers (staircase experiment) [40] (Figure 2). Topp and co-workers used a similar Hill function ( $n=2, C_{\mathrm{Hf}}=7.8$ $\mathrm{mM}$ ) for insulin secretion based on (rat) data from Malaisse [67]. Compared to 
Table 1 Summary of Hill function (eq. 2) parameters used in the present model (Figure 1, eq. 3-9)

\begin{tabular}{|c|c|c|c|c|c|}
\hline Model & Var. & $\mathrm{C}_{\mathrm{Hf}}$ & $n$ & $R_{\max }$ & Comments \\
\hline $\begin{array}{l}R_{\text {oxy, }} \text { oxygen } \\
\text { consumption, } \\
\text { base }\end{array}$ & $c_{\text {oxy }}$ & $1 \mu \mathrm{M}$ & 1 & $-0.034 \mathrm{~mol} / \mathrm{m}^{3} / \mathrm{s}$ & Cut to 0 below critical value, $c_{\text {oxy }}<C_{c r, o x y}$ \\
\hline $\begin{array}{l}R_{\text {oxy, }} \text { oxygen } \\
\text { consumption, } \phi_{\mathrm{o}, \mathrm{g}} \\
\text { metabolic part }\end{array}$ & $c_{\text {gluc }}$ & $7 \mathrm{mM}$ & 2.5 & N/A & $\begin{array}{l}\text { Due to increasing metabolic demand; } \\
\text { parallels second-phase insulin secretion } \\
\text { rate. }\end{array}$ \\
\hline $\begin{array}{l}R_{\text {gluc, }} \text { glucose } \\
\text { consumption }\end{array}$ & $c_{\text {gluc }}$ & $10 \mu \mathrm{M}$ & 1 & $-0.028 \mathrm{~mol} / \mathrm{m}^{3} / \mathrm{s}$ & $\begin{array}{l}\text { Contrary to oxygen, has no significant } \\
\text { influence on model results. }\end{array}$ \\
\hline $\begin{array}{l}R_{\text {ins,ph2, insulin }} \\
\text { secretion rate, } \\
\text { second-phase }\end{array}$ & $c_{\text {gluc }}$ & $7 \mathrm{mM}$ & 2.5 & $3 \times 10^{-5} \mathrm{~mol} / \mathrm{m}^{3} / \mathrm{s}$ & $\begin{array}{l}\text { Total secretion rate is modulated by local } \\
\text { oxygen availability (last row). }\end{array}$ \\
\hline $\begin{array}{l}R_{\text {ins,ph1, insulin }} \\
\text { secretion rate, } \\
\text { first-phase }\end{array}$ & $\partial c_{\text {gluc }} / \partial t$ & $0.03 \mathrm{mM} / \mathrm{s}$ & 2 & $21 \times 10^{-5} \mathrm{~mol} / \mathrm{m}^{3} / \mathrm{s}$ & $\begin{array}{l}\text { Modulated via eq. } 8 \text { to have maximum } \\
\text { sensibility around } c_{\text {gluc }}=5 \mathrm{mM} \text { and be } \\
\text { limited at very large or low } c_{\text {gluc. }}\end{array}$ \\
\hline $\begin{array}{l}\text { Insulin secretion } \\
\text { rate, } \phi_{o, g} \text { oxygen } \\
\text { dependence }\end{array}$ & $c_{\text {oxy }}$ & $3 \mu \mathrm{M}$ & 3 & N/A & $\begin{array}{l}\text { To abruptly limit insulin secretion if } c_{\text {oxy }} \\
\text { becomes critically low. }\end{array}$ \\
\hline
\end{tabular}

rodents, human insulin response is left-shifted, and a half-maximal response for a glucose concentration around $7 \mathrm{mM}$ seems reasonable [40,68]. The activity of glucokinase, which serves as glucose sensor in $\beta$-cells and is also generally considered as rate-limiting for their glucose usage, shows a sigmoid-type dependence on $c_{\text {gluc }}$ (i.e., eq. 2 with $C_{\mathrm{Hf}, \text { gluc }}=8.4 \mathrm{mM}, n_{\text {gluc }}=1.7[69]$ or $\left.C_{\mathrm{Hf} \text {,gluc }}=7.0 \mathrm{mM}, n_{\text {gluc }}=1.7[70]\right)$ in general agreement with eqs. 5 and 6 and their parameterization (Table 1). $R_{\max , \text { ins2 }}$ corresponds to a maximum (second phase) secretion rate of $\sim 20 \mathrm{pg} / \mathrm{IEQ} / \mathrm{min}$ for human islets $[37,40,71]$.

To incorporate a simple model of the first-phase response, we also added a component that depends on the glucose time-gradient $\left(c_{t}=\partial c_{\text {gluc }} / \partial t\right)$. This is non-zero only when the glucose concentration is increasing, i.e., only when $c_{\mathrm{t}}>0$. Again, a Hill-type sigmoid response was assumed to ensure a plateau:

$$
R_{\text {ins, ph } 1}=R_{\max , \text { ins } 1} \frac{\left(\frac{\partial c_{\text {gluc }}}{\partial t}\right)^{n_{\text {ins } 1, \text { gluc }}}}{\left(\frac{\partial c_{\text {gluc }}}{\partial t}\right)^{n_{\text {ins } 1, \text { gluc }}}+C t_{\text {Hf, ins } 1, g l u c}^{n_{\text {ins }, \text { lluc }}}} \cdot \sigma_{i 1, g}\left(c_{g l u c}\right)
$$

with $n_{\text {ins1,gluc }}=2, C t_{\mathrm{Hf}, \text { ins1,gluc }}=0.03 \mathrm{mM} \mathrm{s}^{-1}$, and $R_{\text {max,ins } 1}=21.0 \times 10^{-5} \mathrm{~mol} \mathrm{~m}^{-3} \mathrm{~s}^{-1}$. These parameters are more difficult to directly calibrate from existing data on insulin responses to stepwise glucose increases; hence, they have to be considered as exploratory settings. Constant glucose ramps have been explored with perifused rat islets in an attempt to quantify these responses [72]; however, the gradients used there are too small $(1.5-4.5 \mu \mathrm{M} / \mathrm{s})$ to allow a clear separation between first-and second-phase responses for quantitation. The $C t_{\mathrm{Hf}}$ value used here $(0.03 \mathrm{mM} / \mathrm{s})$ was selected so as to give an approximately linear response for a range that likely covers normal physiologic conditions (e.g., $5 \mathrm{mM}$ increase in $10-20 \mathrm{~min}$ : $0.005-0.01 \mathrm{mM} / \mathrm{s}$ ) as well as dynamic perifusion conditions (e.g., 2-6 $\mathrm{mM}$ increases in $1 \mathrm{~min}$ : 0.03-0.10 mM/s). A completely linear (i.e., proportional) glucose gradient dependent term has been used in a few previous models mainly following Jaffrin [20,26,72-74] (one of them [73] also allowing modulation of the proportionality constant by glucose concentration). Here, one 
additional modulating function, $\sigma_{\mathrm{i} 1, \mathrm{~g}}$ has also been incorporated to reduce this gradient-dependent response for islets that are already operating at an elevated secondphase secretion rate and to maximize it around $c_{\text {gluc }}$ values where islets are likely to be most sensitive $\left(C_{\mathrm{m}}=5 \mathrm{mM}\right)$ using a derivative of a sigmoid function:

$$
\sigma_{i 1, g}\left(c_{g l u c}\right)=\frac{4 c_{g l u c}^{4} C_{m}^{4}}{\left(c_{g l u c}^{4}+C_{m}^{4}\right)^{2}}
$$

With all these, total insulin release is obtained as the sum of first-and second-phase releases and an additional modulating function to account for the limiting effect of oxygen availability, which can become important in the core region of larger avascular islets especially under hypoxic conditions:

$$
R_{i n s}=\left(R_{i n s, p h 1}+R_{i n s, p h 2}\right) \cdot \varphi_{i, o}\left(c_{o x y}\right)
$$

We assumed an abrupt Hill-type (eq. 2$)$ modulating function as $\phi_{i, o}\left(c_{\text {oxy }}\right)$ with $n_{\text {ins,oxy }}=$ 3 and $C_{\mathrm{Hf} \text {,ins,oxy }}=3 \mu \mathrm{M}\left(p_{\mathrm{Hf} \text {,ins,oxy }}=2 \mathrm{mmHg}\right)$ so that insulin secretion starts becoming limited for local oxygen concentrations that are below $\sim 6 \mu \mathrm{M}$ (corresponding to a partial pressure of $p_{\mathrm{O} 2} \approx 4 \mathrm{mmHg}$ ) (Additional file 1, Figure $\mathrm{S} 1$ ). This is a somewhat similar, but mathematically more convenient function than the bilinear one introduced by Avgoustiniatos [75] and used by Colton and co-workers [76] to account for insulin secretion limitations at low oxygen $\left(p_{\mathrm{O} 2}<5.1 \mathrm{mmHg}\right.$ assumed by them) as it is a smooth sigmoid function with a continuous derivative (Additional file 1, Figure S1).

For a correct time-scale of insulin release, an extra compartment had to be added; otherwise insulin responses decreased too quickly compared to experimental observations ( 1 min vs. 5-10 min). Hence, insulin is assumed to be first secreted in a 'local' compartment (Figure 1) in response to the current local glucose concentration $\left(R_{\text {ins }}\right.$, eq. 9) and then released from here following a first order kinetics $\left[\mathrm{d} c_{\text {insL }} / \mathrm{d} t=R_{\text {ins }}\right.$ $k_{\text {insL }}\left(c_{\text {insL }}-c_{\text {ins }}\right) ; k_{\text {insL }}=0.003 \mathrm{~s}^{-1}$, corresponding to a half-life $t_{1 / 2}$ of approximately 4 min]. 'Local' insulin was modeled as an additional concentration with the regular convection model (eq. 1), but having a very low diffusivity $\left(D_{\text {insL,t }}=1.0 \times 10^{-16} \mathrm{~m}^{2} \mathrm{~s}^{-1}\right)$. Throughout the entire model building process, special care was taken to keep the number of parameters as low as possible to avoid over-parameterization [77]; however, inclusion of this compartment was necessary. The model has been parameterized by fitting experimental insulin release data from two detailed concentration-dependence perifusion studies: one concentrating on the effect of glucose using isolated human islets [40] and one concentrating on the effect of hypoxia using isolated rat islets [27].

\section{Fluid dynamics model}

To incorporate media flow in the perifusion tube, these convection and diffusion models need to be coupled to a fluid dynamics model. Accordingly, the incompressible Navier-Stokes model for Newtonian flow (constant viscosity) was used for fluid dynamics to calculate the velocity field $\mathbf{u}$ that results from convection [32,41]:

$$
\begin{gathered}
\rho \frac{\partial \mathbf{u}}{\partial t}-\eta \nabla^{2} \mathbf{u}+\rho(\mathbf{u} \cdot \nabla) \mathbf{u}+\nabla p=\mathbf{F} \\
\nabla \cdot \mathbf{u}=0
\end{gathered}
$$


Here, $\rho$ denotes density $\left[\mathrm{kg} \mathrm{m}^{-3}\right], \eta$ viscosity $\left[\mathrm{kg} \mathrm{m}^{-1} \mathrm{~s}^{-1}=\mathrm{Pa} \mathrm{s}\right], p$ pressure $[\mathrm{Pa}, \mathrm{N} \mathrm{m}$ $\left.{ }^{2}, \mathrm{~kg} \mathrm{~m}^{-1} \mathrm{~s}^{-2}\right]$, and $\mathbf{F}$ volume force $\left[\mathrm{N} \mathrm{m}^{-3}, \mathrm{~kg} \mathrm{~m}^{-2} \mathrm{~s}^{-2}\right]$. The first equation is the momentum balance; the second one is simply the equation of continuity for incompressible fluids. The flowing media was assumed to be an essentially aqueous media at body temperature; i.e., the following values were used: $T_{0}=310.15 \mathrm{~K}, \rho=993 \mathrm{~kg} \mathrm{~m}^{-3}$, $\eta=0.7 \times 10^{-3}$ Pa s, $c_{\mathrm{p}}=4200 \mathrm{~J} \mathrm{~kg}^{-1} \mathrm{~K}^{-1}, k_{\mathrm{c}}=0.634 \mathrm{~J} \mathrm{~s}^{-1} \mathrm{~m}^{-1} \mathrm{~K}^{-1}, \alpha=2.1 \times 10^{-4} \mathrm{~K}^{-1}$. As previously [33], incoming media was assumed to be in equilibrium with atmospheric oxygen and, thus, have an oxygen concentration of $c_{\text {oxy,in }}=0.200 \mathrm{~mol} \mathrm{~m}^{-3}(\mathrm{mM})$ corresponding to $p_{\mathrm{O} 2} \approx 140 \mathrm{mmHg}$. A number of GSIR perifusion studies including [40] used solutions gassed with enriched oxygen (e.g., $95 \% \mathrm{O}_{2}+5 \% \mathrm{CO}_{2} ; p_{\mathrm{O} 2} \approx 720$ $\mathrm{mmHg}$ ); however, with the islet sizes used here, atmospheric oxygen already provides sufficient oxygenation so that the extra oxygen has no effect on model-calculated insulin secretion (see Results section). Inflow velocity was set to $v_{\text {in }}=10^{-4} \mathrm{~m} \mathrm{~s}^{-1}$ (corresponding to a flow rate of $0.1 \mathrm{~mL} / \mathrm{min}$ in a $\sim 4 \mathrm{~mm}$ tube), and along the inlet, a parabolic inflow velocity profile was used: $4 v_{\text {in }} s(1-s), s$ being the boundary segment length.

\section{Model implementation}

The models were implemented in COMSOL Multiphysics 3.5 (formerly FEMLAB; COMSOL Inc., Burlington, MA) and solved as time-dependent (transient) problems allowing intermediate time-steps for the solver. Computations were done with the Pardiso direct solver as linear system solver with an imposed maximum step of $0.5 \mathrm{~s}$, which was needed to not miss changes in the incoming glucose concentrations that could be otherwise overstepped by the solver. With these setting, all computation times were reasonable being about real time; i.e., about $1 \mathrm{~h}$ for each perifusion simulations of $1 \mathrm{~h}$ interval.

As a representative case, a $2 \mathrm{D}$ cross-section of a cylindrical tube with two spherical islets of 100 and $150 \mu \mathrm{m}$ diameter was used allowing for the possibility of either free or encapsulated islets (capsule thickness $l=150 \mu \mathrm{m}$; fluid flowing from left to right) (Figure 3). Stepwise increments in the incoming glucose concentration were implemented using again the smoothed Heaviside step function at predefined time points $t_{i}, c_{\text {gluc }}$ $=c_{\text {low }}+\Sigma c_{\text {step,i }}$ flc1hs $\left(t-t_{i}, \tau\right)$. For FEM, COMSOL's predefined 'Extra fine' mesh size was used (5,000-10,000 mesh elements; Figure 3). In the convection and diffusion models, the following boundary conditions were used: insulation/symmetry, $\mathbf{n}(-D \nabla c$ $+c \mathbf{u})=0$, for walls, continuity for islets. For the outflow, convective flux was used for insulin, glucose, and oxygen, $\mathbf{n}(-D \nabla c)=0$. For the inflow, inward flux was used for all components with zero for insulin $\left(N_{0}=0\right), c_{\text {gluc }} v_{\text {in }}$ for glucose, and $c_{\text {oxy,in }} v_{\text {in }}$ for oxygen. In the incompressible Navier-Stokes model, no slip $(\mathbf{u}=0)$ was used along all surfaces corresponding to liquid-solid interfaces. For the outlet, pressure, no viscous stress with $p_{0}=0$ was imposed.

For visualization of the results, surface plots were used for $c_{\text {ins }}, c_{\text {oxy }}$, and $R_{\text {ins. }}$. For 3D plots, $c_{\text {ins }}$ was also used as height data. A contour plot (vector with isolevels) was used for $c_{\text {gluc }}$ to highlight the changes in glucose. To characterize fluid flow, arrows and streamlines for the velocity field were also used. Animations were generated with the same settings used for the corresponding graphs. Total insulin secretion as a function 


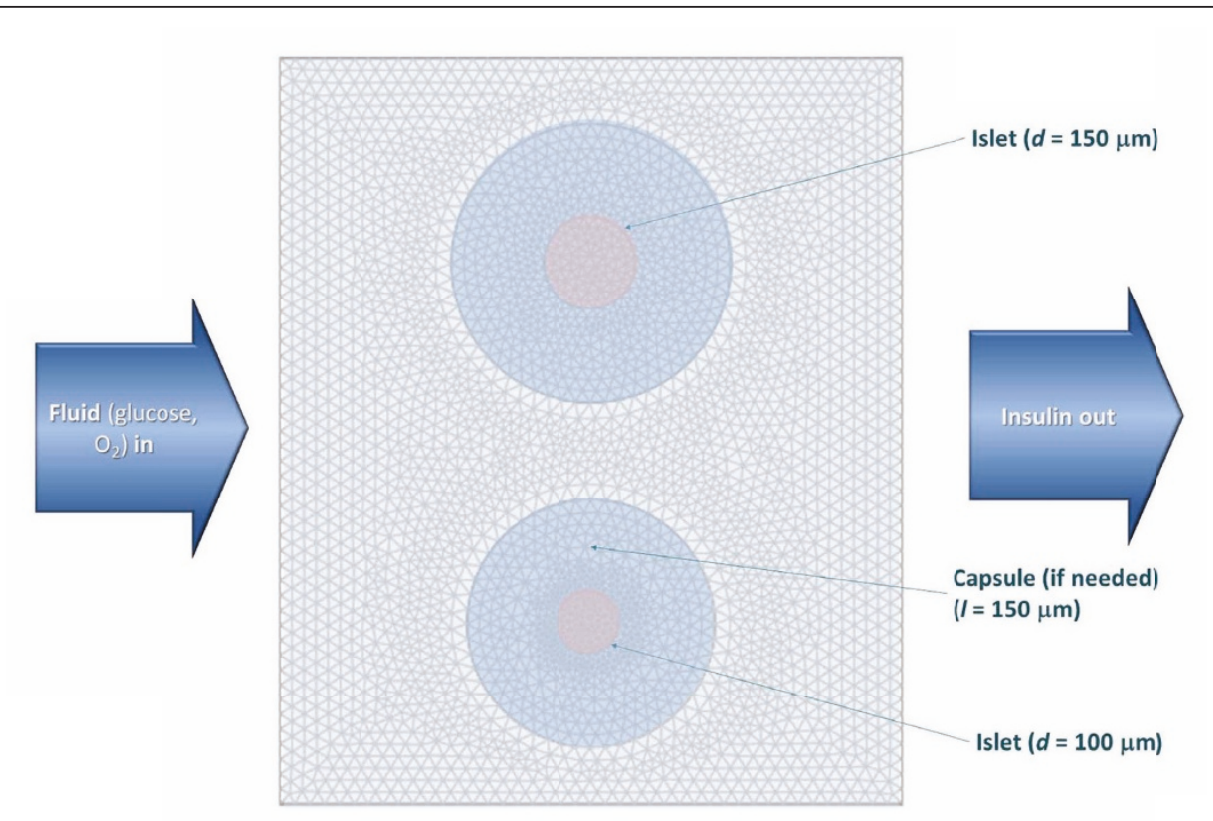

Figure 3 Geometry and a representative mesh used for the present FEM model. Two representative spherical islets, which can be either free or encapsulated, are included in a tube with fluid flowing from left to right.

of time was visualized using boundary integration for the total flux along the outflow boundary.

\section{Results and Discussion}

First-and second-phase insulin responses

Following implementation of the model, the values of the adjustable parameters of eqs. 4-9 were selected (Table 1) so as to fit insulin secretion data from islet perifusion experiments with detailed dose responses for glucose-[40,78] and oxygen-dependence [27]. For this purpose, model-predicted insulin responses to stepwise increments in the incoming glucose content were calculated as boundary integrals on the exiting surface of the out-flowing fluid, and these were then fitted to the experimental insulin responses measured as a function of time. First, the parameters of the second-phase response (eq. 6) were fitted to the results of the staircase experiment [40], then those of the first-phase response (eq. 7 and 8). Fine-tuning of the values has been done in a few iterative rounds to also fit the oxygen dependence [27]. As Figure 4 shows, acceptable quantitative agreement can be obtained for both phase 1 and phase 2 responses of the insulin secretion of human islets as measured recently in detailed experiments [40]. The amplitude of the insulin response, which depends on the mass of functional islets present, was adjusted for best fit, but it is within the expected range if calculated for the corresponding number of islet equivalents (IEQ). During the modeling [79], it became apparent that in order to have a correct time-scale and not a very short-term first-phase release, some delay mechanism has to be introduced. After exploring several possibilities, the delay was modeled by incorporation of a 'localized' insulin compartment (e.g., intracellular) from which insulin is then released to the surroundings via 


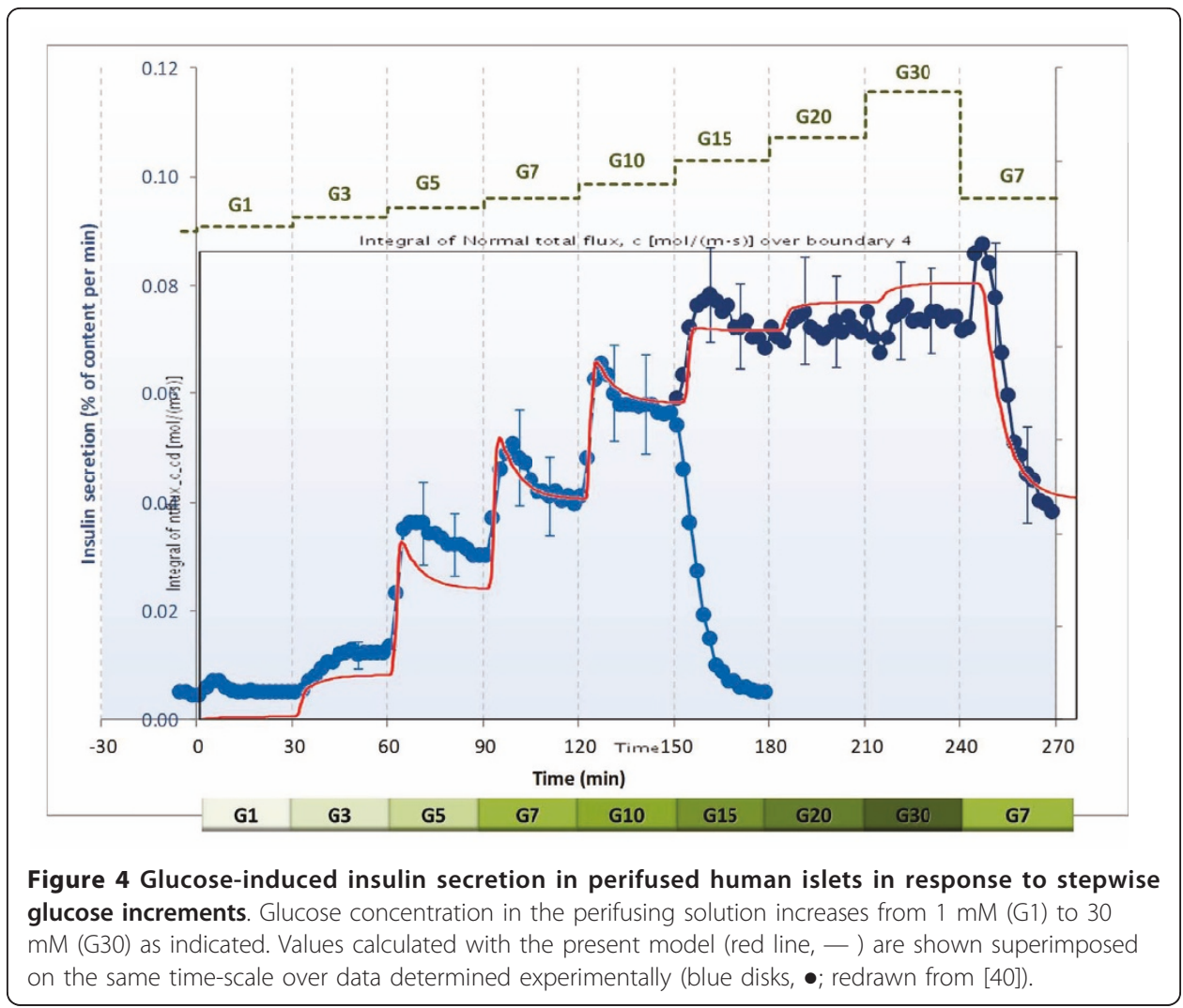

first order kinetics $\left(k_{\text {insL }}\right)$ (Figure 1). A main reason for this choice was that conceptually, to a good extent, this insulin secreted and stored 'locally' can be considered as the insulin in the readily releasable pool (RRP) of granules in current dynamic cellular models of biphasic insulin secretion [37,65]. It is being filled in response to glucose stimulation $\left(R_{\text {ins }}\right.$, eq. 9$)$ and then gradually emptied $\left(k_{\text {insL }}\right)$. Our goal at this point, is not to model the detailed cellular and subcellular mechanisms responsible for the biphasic secretion and the staircase response $[37,65,66]$, but to identify functional forms for local responses $\left(R_{\text {ins }}\right)$ that when integrated with the descriptions of spatial distribution of the relevant concentrations can give an adequate quantitative description ( $c_{\text {gluc }}, c_{\text {oxy }} \rightarrow R_{\text {ins }} \rightarrow c_{\text {ins }}$ ). Most perifusion experiments intended to assess islet quality are performed as single step low-high-low glucose perifusion experiments; a fit for one such data is shown in Figure 5. Again, except for an underestimate of the first-phase peak, acceptable agreement is obtained. First-phase insulin secretion has been shown to be greater following a larger step-up in glucose to the same final value (e.g., both in human [40] and in mouse [80] islets). The present model should account for this as its first-phase insulin secretion rate is determined by the glucose gradient, which increases directly with the size of the step-up; however, some fine-tuning of the parameters is still needed. The predicted first-phase decay (resulting from $\left.k_{\text {insL }}\right)$ may be a bit too slow $\left(t_{1 / 2} \approx 4 \mathrm{~min}\right.$ ); however, the prediction of the second-phase decay is more adequate, and to keep the model as simple as possible, we chose to use only one single 'local' insulin 'compartment', hence, a single first-order release rate $k_{\text {insL }}$. 


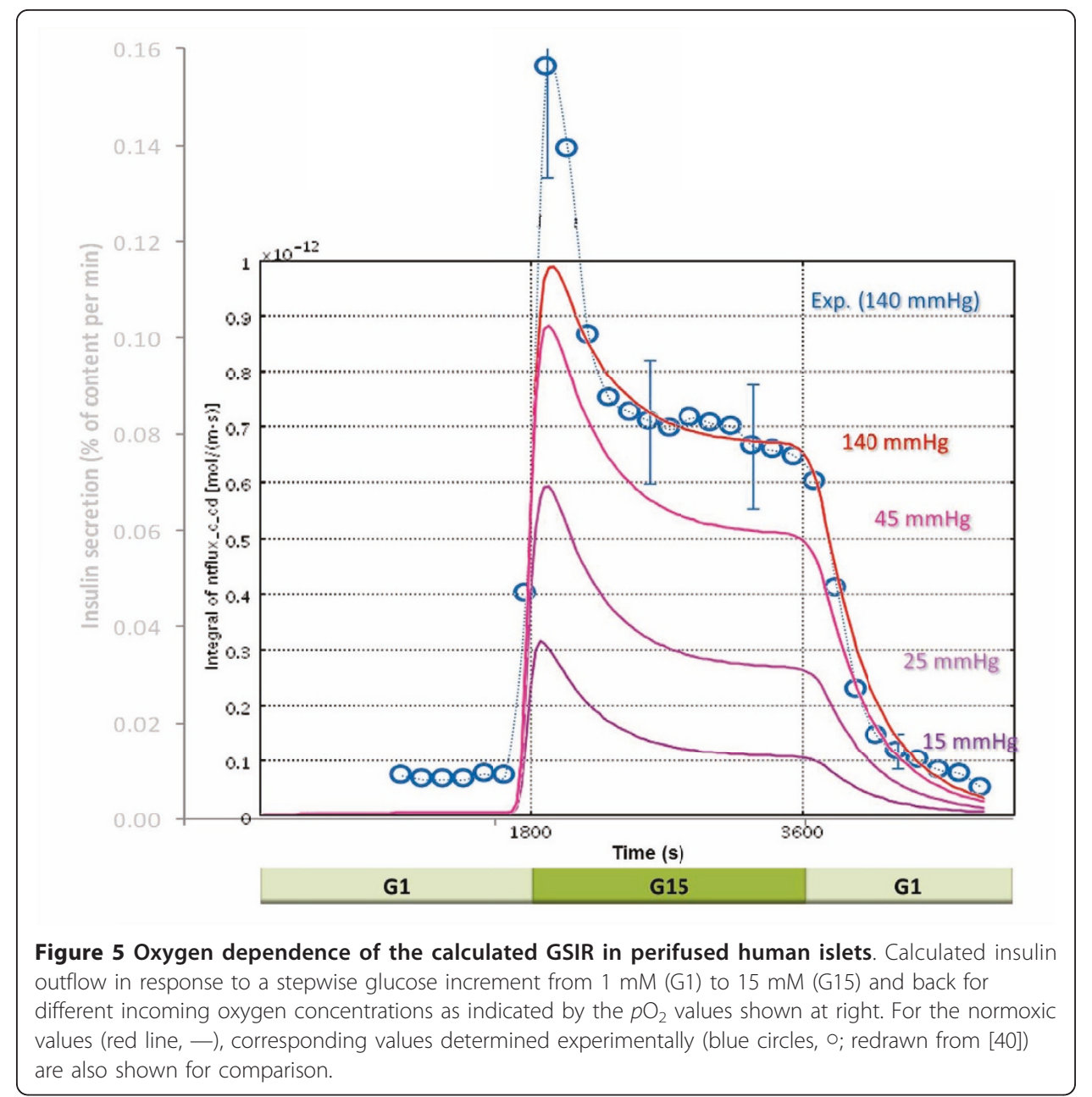

\section{Oxygen dependence}

Because oxygen diffusion is a limiting factor in avascular islets, hypoxia can limit insulin secretion. The oxygen dependence of local insulin release has been parameterized so as to fit the only detailed data available, which, however, are for rat islets [27]. Insulin secretion profiles calculated here for different incoming oxygen concentrations in response to a single glucose step are shown in Figure 5 for a few representative cases. As Figure 6 shows, they give a good quantitative fit of the experimental data of reference [27]. The problem, however, is complicated by the fact that due to the larger diffusion distance, hypoxia is much more severe in the core regions of larger islets [33]; hence, hypoxia will have different effects on the insulin response of differently sized islets. This can be seen in Figure 7 and Figure 8, which show the calculated spatial distributions of insulin, oxygen, and glucose concentrations under normoxic and slightly hypoxic conditions as surface plots. Figure 9 provides further illustration by comparing oxygen concentrations and insulin secretion rates along a vertical cross section of the two islets.

Accordingly, the overall experimental response to hypoxic conditions will depend on the size-distribution of the islet sample. Human islets seem to follow a Weibull distribution with the expected value of islet diameter being around $95 \mu \mathrm{m}$ and the expected 


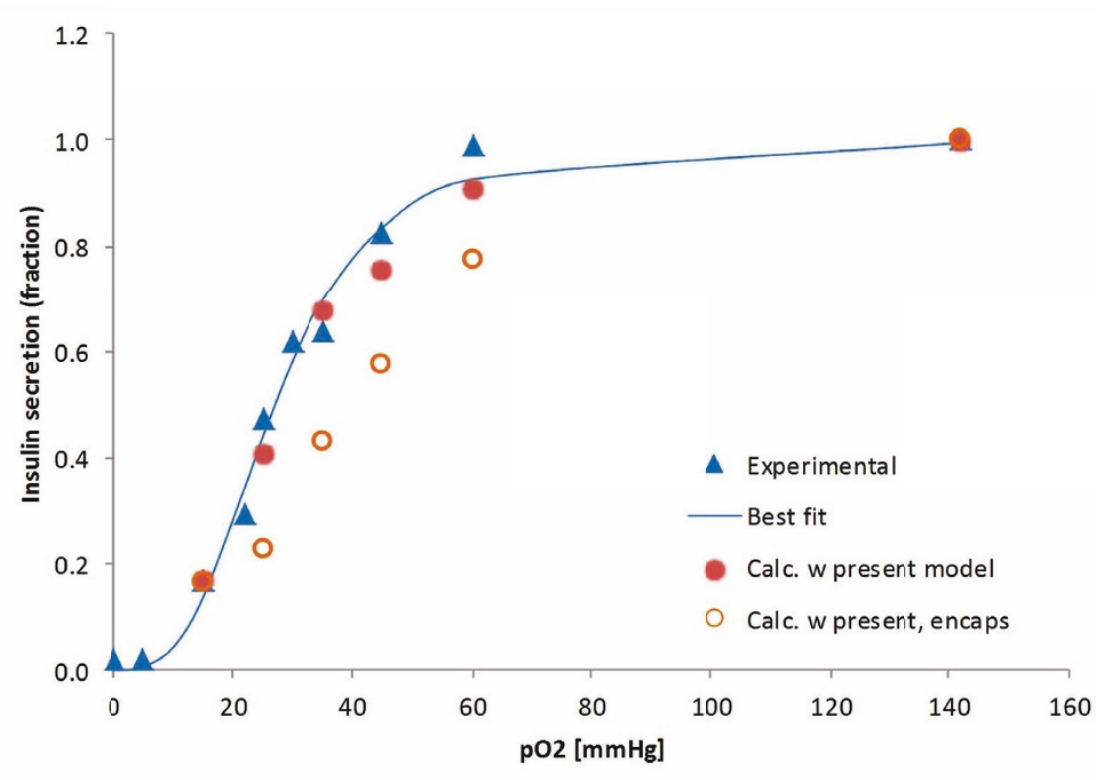

Figure 6 Influence of oxygen concentration on the insulin secretion rate of perifused islets. Data represent the fraction of normoxic (second-phase) rate at various oxygen levels in the perifusing media; experimental data (blue triangles) are from [27] and values calculated here are shown as red disks for free islets and orange circles for encapsulated islets. The size-distribution of the islet sample influences these results as larger islets are more severely affected by hypoxia.

value of islet volume being $1.2 \times 10^{6} \mu \mathrm{m}$ (corresponding to an islet with $d=133 \mu \mathrm{m}$ ) [3]. In other words, most (human) islets are expected to have a diameter around 100 $\mu \mathrm{m}$, but most of the islet mass (volume) is coming from islets with a diameter around $150 \mu \mathrm{m}$, which has been traditionally used as the standard islet (islet equivalent, IEQ) [81,82]. Consequently, we chose two islets with $d=100$ and $150 \mu \mathrm{m}$ as representative for our simplified modeling.

It is important to note that even though local insulin release is becoming limited only for oxygen concentrations below $4 \mathrm{mmHg}(\approx 6 \mu \mathrm{M}$; eq. 9), the total insulin secretion of the islets starts decreasing rapidly if surrounding oxygen levels drop below $\sim 50$ $\mathrm{mmHg}$ and is already half-maximal around $25 \mathrm{mmHg}$ (Figure 6). The reason, of course, is that oxygen concentrations in the core of larger islets are considerable less than in the surrounding media due to diffusion limitations (see Figure 8 and 9). It is also worth noting that overall insulin response remains essentially unchanged until oxygen pressures decrease down to $\sim 50 \mathrm{mmHg}$ (Figure 6), values that are present in well vascularized tissues, and then decreases rapidly. This agrees well even with results of in vivo experiments in dogs suggesting that moderate hypoxia $\left(p_{\mathrm{O} 2} \approx 40 \mathrm{mmHg}\right)$ does not affect insulin response, whereas more severe hypoxia $\left(p_{\mathrm{O} 2} \approx 25 \mathrm{mmHg}\right.$ ) markedly inhibits it [83]. A number of GSIR perifusion studies including [40] used solutions gassed with enriched oxygen (e.g., $95 \% \mathrm{O}_{2}+5 \% \mathrm{CO}_{2} ; p_{\mathrm{O} 2} \approx 720 \mathrm{mmHg}$ ). Compared to atmospheric oxygen $\left(p_{\mathrm{O} 2} \approx 140 \mathrm{mmHg}\right)$, this does not produces any changes in the insulin profile calculated with the present model (e.g., Figure 4) since with the islet sizes used here atmospheric oxygen already provides sufficient oxygenation so that insulin secretion is not limited (Figure 8A, Figure 9A). On the other hand, transplanted 


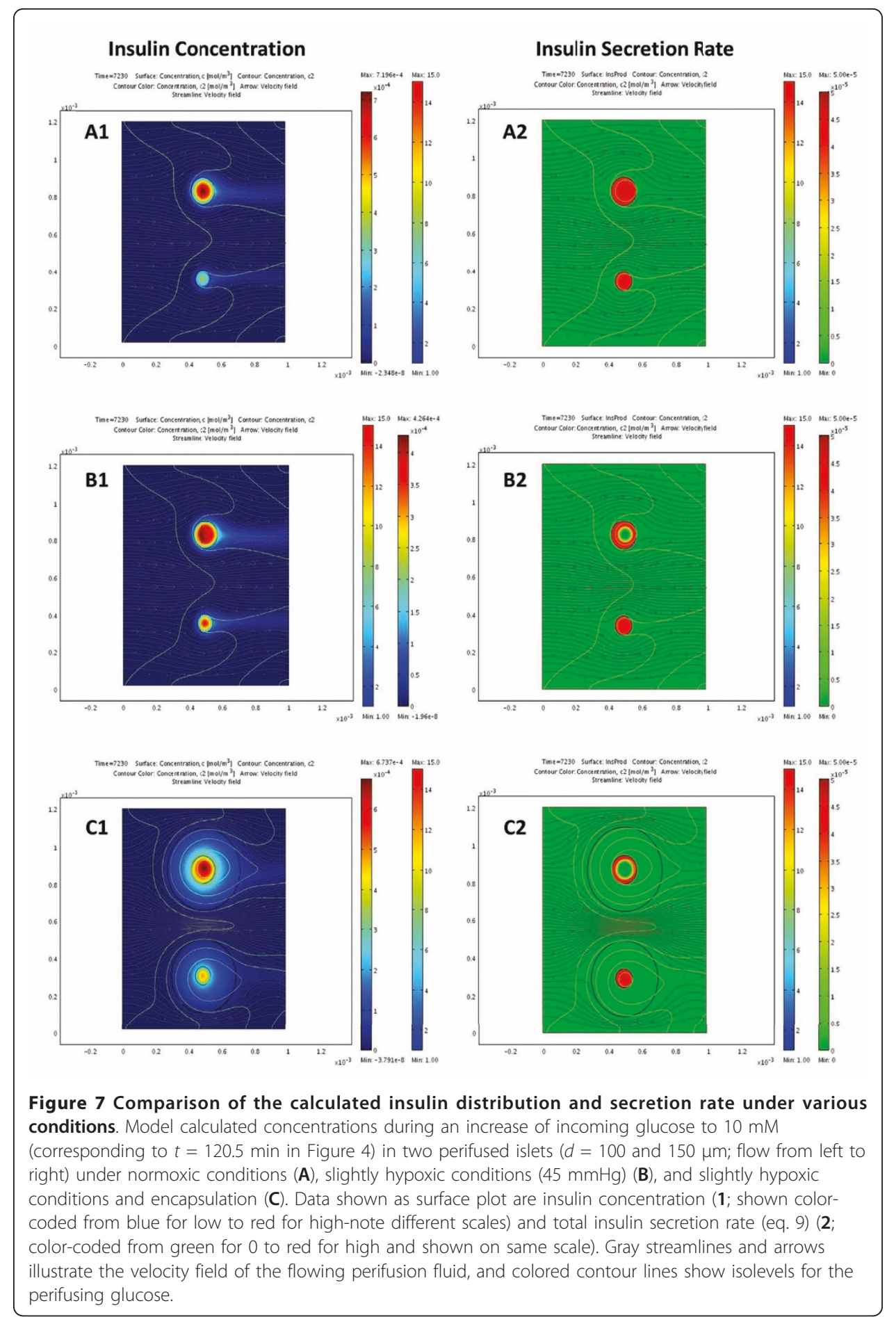

islets are likely to be subject to oxygen levels below $50 \mathrm{mmHg}$ [84] depending on the seeding density and the vascularization of the surrounding tissue, which can further limit their insulin secreting ability. Availability of oxygen is the main limiting factor because, under physiological conditions, oxygen concentrations are considerably lower than glucose concentrations (e.g., around 0.05-0.2 mM vs. 3-15 mM) [62], and this is well illustrated by the present calculation in Figure 8 that compares oxygen and 


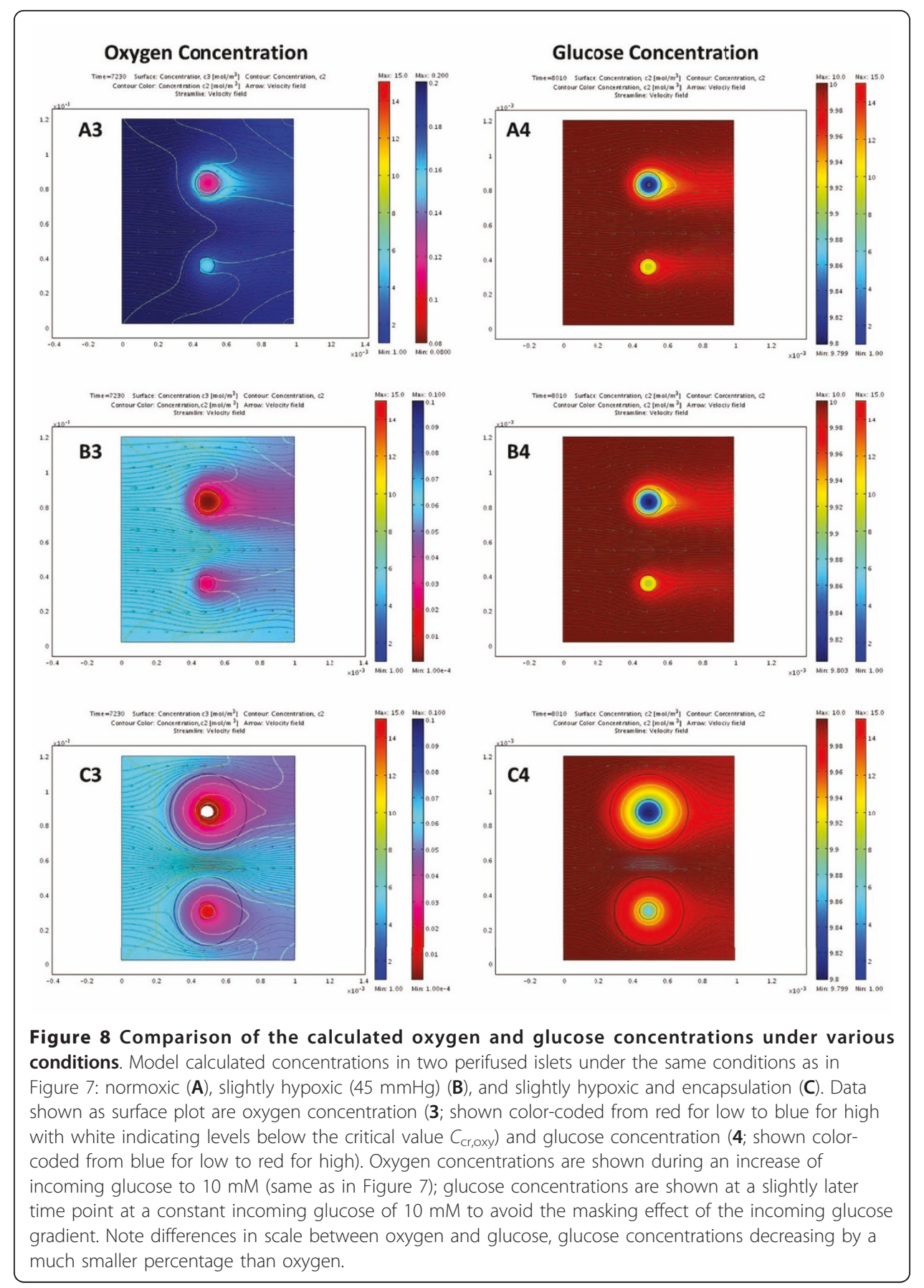

glucose concentrations across the islets. Whereas glucose concentrations in the center of larger islets are only a few percent lower than at the periphery, oxygen concentrations in the center are considerably lower than at the periphery. R. T. Kennedy and co-workers measured somewhat larger glucose concentration decreases in the center of cultured islets (10-20\%) [45], but even those are much less severe than the corresponding oxygen decreases.

With the calibrated model, detailed simulations for arbitrary inflow conditions and for arbitrary islet arrangements can be performed, and corresponding detailed graphics 

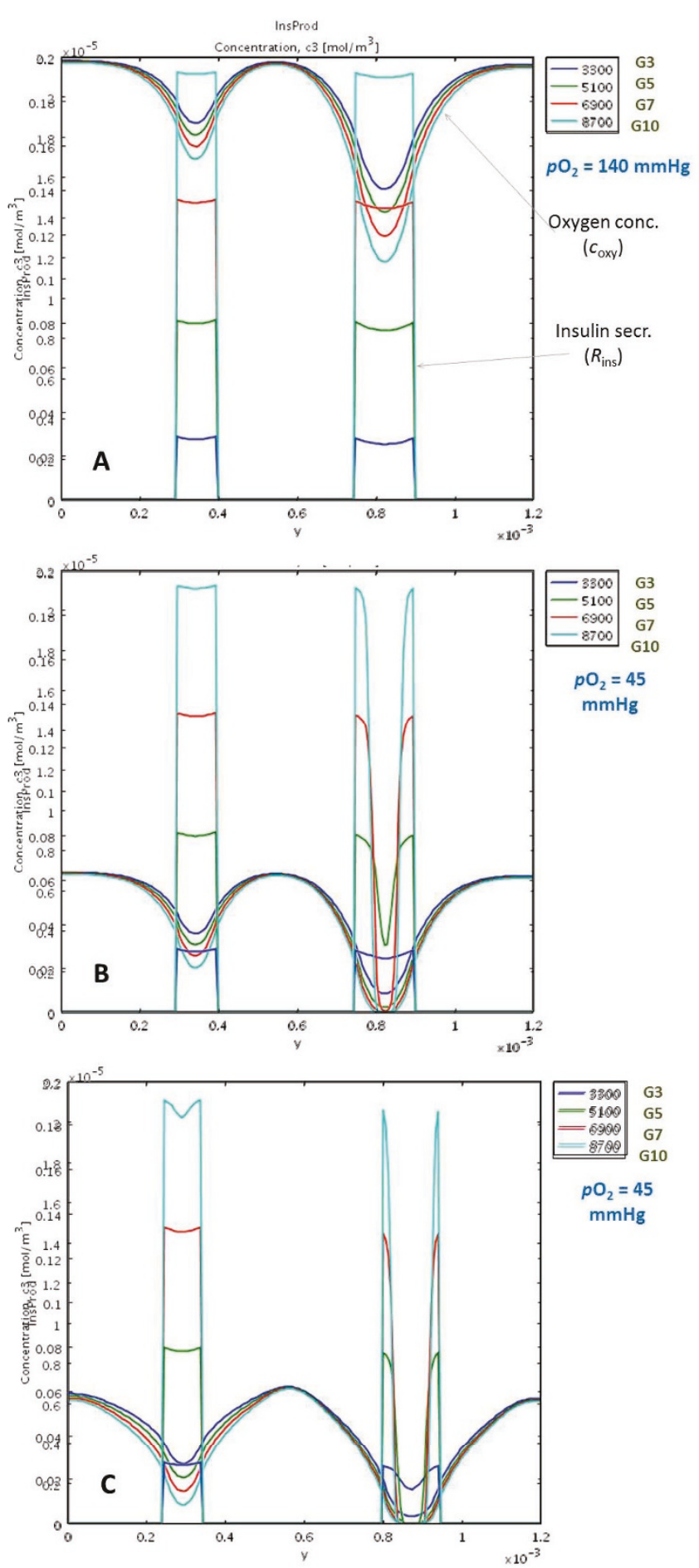

Figure 9 Comparison of oxygen levels and insulin secretion rates along a vertical cross section Calculated values along the vertical mid-section of Figure 3 (or Figure 7) through the two perifused islets under normoxic conditions (atmospheric oxygen, $140 \mathrm{mmHg}$ ) (A), hypoxic conditions (resembling tissue oxygen concentrations, $45 \mathrm{mmHg}$ ) (B), and hypoxic conditions and encapsulation (C). The two sets of color-coded curves in each figure indicate calculated oxygen concentrations and insulin secretion rates, respectively at various time-points corresponding to glucose concentrations of 3, 5, 7, and $10 \mathrm{mM}$. At oxygen concentrations that transplanted islets are likely to encounter in their surrounding tissue $(\sim 40$ $\mathrm{mmHg}$, the insulin secretion of the core region of larger islets is severely compromised. 
and animations can easily be generated. For example, calculated insulin, oxygen, and glucose concentrations along the perifusion chamber with two islets during a glucose gradient are shown in Figure 7 together with the insulin secretion rates. A set of similar results is shown in Figure 9 along a vertical cross-section through the middle of these figures. To illustrate the easy generalizability of the present approach, Additional file 1, Figure S2 shows the results of calculations obtained for a case where a supporting filter was included in the tube. While this perturbs the flow, it has essentially no effect on the overall insulin output justifying the simplifying assumptions made for the present geometry (Figure 3). Increases in the perifusion rate (e.g., up to ten-fold) also have no significant effect on calculated insulin output.

Figure 10 shows 3D graphs with insulin as height data and color-coded for the oxygen concentrations to further highlight the results of decreasing oxygen concentration in the core region of larger islets. A corresponding set of animations are included as Supporting Information to illustrate the time-course of the first-and second-phase responses following a glucose step (Additional file 2, Video S1; Additional file 3, Video $\mathrm{S} 2)$. At normoxic conditions $\left(p_{\mathrm{O} 2}=140 \mathrm{mmHg}\right.$ in the incoming media), the core region of even large islets is still sufficiently oxygenized due to the flowing media; hence, their insulin secretion is not limited. However, this is no longer true for hypoxic
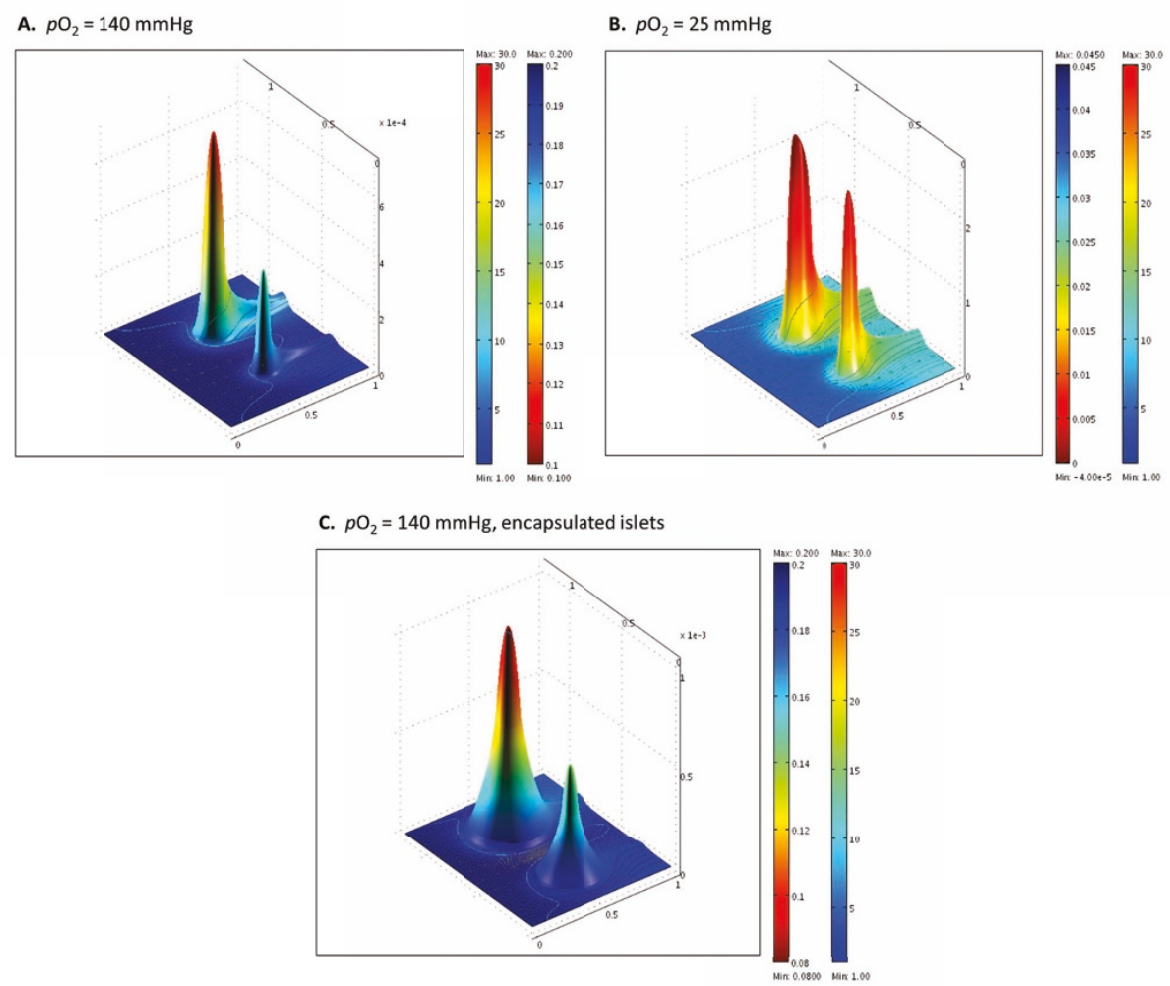

Figure 10 Calculated insulin concentrations shown as height data. Surfaces are color-coded for oxygen concentration (blue high, red low) for the same configuration and time-point shown in Figure 7 for free islets in normoxic ( $\left.p_{\mathrm{O} 2}=140 \mathrm{mmHg}\right)(\mathbf{A})$ and hypoxic conditions $\left(p_{\mathrm{O} 2}=25 \mathrm{mmHg}\right)(\mathbf{B})$ as well as for encapsulated islets in normoxic conditions (C). The insulin secreting ability of the large islet is more severely affected by hypoxia as clearly indicated by the changes in relative height between $\mathbf{A}$ and $\mathbf{B}$ (note different scales). 
conditions as illustrated by Figure 9B or by Figure 10B showing the corresponding results for $p_{\mathrm{O} 2}$ of 45 and $25 \mathrm{mmHg}$, respectively in the incoming media. Contrary to the previous case, the two islets are predicted to secret about similar insulin amounts despite their different sizes due to the more severe oxygen limitations in the core region of the larger islet, which restricts insulin secretion to an outside shell only in large islets. These results are in good agreement with observations suggesting that smaller islets tend to perform better in islet transplantation (with or without encapsulation) [85-88].

\section{Encapsulated islets}

In patients with type 1 diabetes mellitus, the transplantation of pancreatic islet cells can normalize metabolic control in a way that has been virtually impossible to achieve with exogenous insulin, and is being explored, in a selected cohort of patients with brittle diabetes, as an experimental therapy $[89,90]$. To avoid the need for lifelong immunosuppression, islet encapsulation using semi-permeable membranes and various techniques has long been explored as a possible approach to develop a bioartificial pancreas-an organ capable of releasing insulin in a biomimetic manner in response to plasma glucose changes [11-13]. Many failed attempts [91] made it clear that minimizing the extra volume of encapsulating material (as well as cellular overgrowth) and the corresponding diffusional limitations are crucial for graft success. Hence, there is a considerable interest in modeling the insulin responses of such devices [20-26].

Encapsulated islets remain avascular; hence, the present software can be easily extended to model their behavior under perifusion or tissue transplant conditions. For example, as Figure 11 shows, simulations with the present model for microencapsulated islets (assuming hydrogel-like encapsulating material of a relatively modest width, $l=150 \mu \mathrm{m})$ predicts that perifusion results in somewhat delayed and dampened insulin response, but insulin response kinetics is maintained to a good degree. This is in good agreement with some experimental results obtained, for example, with alginate microencapsulated islets (using oxygen-enriched perifusion media to minimize the effects of oxygen limitation) [92,93]. However, at lower perifusing oxygen concentrations, such as those mimicking tissue oxygen concentrations that transplanted islets are likely to encounter even in well-vascularized tissue $\left(p_{\mathrm{O} 2}=35-45 \mathrm{mmHg} ; c_{\mathrm{oxy}}=\right.$ $0.05-0.065 \mathrm{mM}$ ), the loss in insulin secreting ability is much more significant as the encapsulated islets here suffer much more heavily from hypoxia (Figure 7, Figure 9, and Figure 10). Whereas, under these conditions, free islets can still secrete insulin at around $70-75 \%$ of their normal rate (and, for transplanted islets, will improve with time as their vasculature is restored), encapsulated islets can only operate at around $50 \%$ of the full rate and their response is especially hampered at larger glucose levels (Figure 6, Figure 11). As nicely illustrated by Figure 7 and Figure 9, only a relatively small percentage of the encapsulated islets cells is able to secrete insulin at full capacity; oxygen diffusion limitations severely restrict the hormone secreting ability of the core regions even at this relatively thin microcapsule size-further emphasizing the need for conformal/nano-coating or other alternative approaches $[13,94,95]$. These results reconfirm the finding of some previous modeling work with cultured or encapsulated islets $[75,76]$, which focused on the limiting effect of hypoxia but without incorporating 


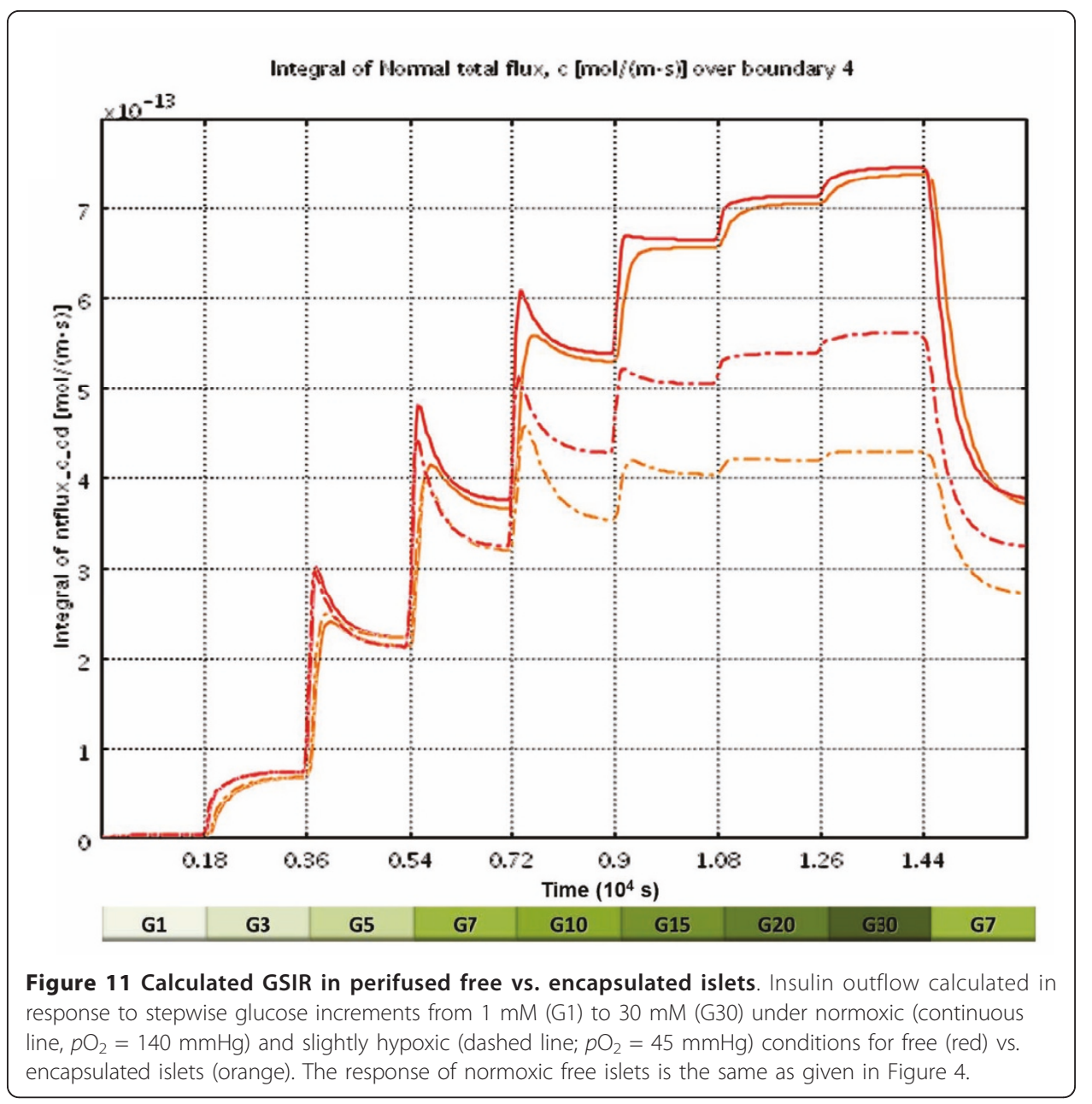

details of the glucose-insulin response, that also suggested that the use of smaller islets (or islet cell aggregates) could reduce the impact of oxygen diffusion limitation.

\section{Modeling considerations}

Obviously, this is still a much simplified, exploratory model; the actual mechanism of glucose-induced insulin secretion in $\beta$-cells is complex and involves various molecularlevel events $[1,2,36,37,39,70,96,97]$. The present model gives an adequate quantitative description of the main distinctive features of insulin release, but, at this stage, does not account for interspecies differences and does not incorporate a number of effects known to affect glucose-induced insulin release including, e.g., amplifiers such as glucagon-like peptide-1 (GLP-1) as well as time-dependent effects (i.e., both time-dependent inhibition and potentiation; e.g., the "glucose priming" effect) [98].

One of the most complex technical control systems that is widely used in industrial control systems and has been suggested as a possibility for the glucose-insulin control system is the proportional-integral-derivative controller (PID controller) [1,8-10]. PID controllers are also particularly promising for closed-loop insulin delivery systems with continuous glucose sensors [8-10,99]. This control loop feedback mechanism uses a combination of proportional, integral, and differential (PID) terms so that the control signal has elements that are functions of the error signal itself $\left(\varepsilon=\xi-\xi_{0}\right.$, the difference 
between the existing output $\xi$ and its desired value $\left.\xi_{\mathrm{o}}\right)$, its integral $\left(\int \varepsilon \mathrm{d} t\right)$, and its differential $(\mathrm{d} \varepsilon / \mathrm{d} t)$. In other words, the controller output signal $\psi$ can be written as a function of time as:

$$
\psi_{P I D}(t)=\alpha_{p} \varepsilon(t)+\alpha_{i} \int_{0}^{t} \varepsilon(\tau) d \tau+\alpha_{d} \frac{d \varepsilon(t)}{d t}
$$

PID control works great in linear systems; however, biological systems are never fully linear: proportional responses are only possible over some limited range as biological responses (e.g., hormone secretion rates, enzymatic degradation rates, nerve firing rates, etc.) are always limited between zero and some maximum value. Biologic systems are always nonlinear, never stationary, but robust, which often comes from coupling of different, overlapping systems [1]. Accordingly, responses in biologic systems are much better described by sigmoid functions; hence, the present suggestion for sigmoid proportional-integral-derivative controllers (SPID controllers) for biologic responses. Use of the Hill function $f_{\mathrm{H}}$ (eq. 2) allows sigmoid responses with limited maximum rates $\left(R_{\max }\right)$ and flexible shapes $(n)$ :

$$
\psi_{S P I D}(t)=\alpha_{p} f_{H}[\varepsilon(t)]+\alpha_{i} f_{H}\left[\int_{t-\theta}^{t} \varepsilon(\tau) d \tau\right]+\alpha_{d} f_{H}\left[\frac{d \varepsilon(t)}{d t}\right]
$$

Here, we used the sigmoid direct (proportional) term to model the oxygen and glucose consumptions as well as the second phase insulin release, and the sigmoid differential term to model the first-phase insulin release (with $c_{\text {gluc }}$ itself as the "error" signal $\varepsilon$; Figure 1). As always, the role of the differential term is to speed up the system; i.e., to give a large correction signal as soon as possible when the monitored value changes suddenly-exactly the role played by the first-phase insulin secretion. In the present model, we could not yet implement an integral term despite a clear need for such a term over a specified time interval to account, for example, for some inertia and/or delay in insulin secretion (integral control is part of several models, i.e., $[8-10,73,99,100])$. However, addition of the extra compartment for delayed insulin release actually incorporates some elements usually accounted for by such an integral term.

\section{Conclusion}

In conclusion, a comprehensive insulin secretion model for avascular pancreatic islets has been implemented using Hill-type sigmoid response functions to describe both glucose and oxygen dependence. Detailed spatial distributions of all concentrations of interest are incorporated and coupled via local consumption and release functions. Following parameterization, good fit could be obtained with experimental perifusion data of human islets. Further optimization of the model is required; however, the present approach makes it relatively straightforward to couple arbitrarily complex hormone secretion and nutrient consumption kinetics with diffusive and even convective transport and run simulations with realistic geometries without symmetry or other restrictions-problems that seriously limited previous glucose-insulin modeling attempts. Because of the general framework of the implementation, the model not only helps in the elucidation of the quantitative aspects of the insulin secretion dynamics, but also 
allows the in silico exploration of various conformations involving cultured, perifused, transplanted, or encapsulated islets including the simulation of GSIR perifusion experiments or the study of the performance of bioartificial pancreas type devices.

\section{Additional material}

Additional file 1: Supporting Information, Figures S1 and S2. Two supporting figures with Figure S1 showing the local oxygen-dependent modulating function and Figure $\mathbf{S 2}$ showing model calculations with a supporting filter included in the perifusion tube.

Additional file 2: Supporting Information, Video S1. Movie file showing the time-course of the insulin response of two islets to a glucose step ( $3 \mathrm{mM} \rightarrow 11 \mathrm{mM} \rightarrow 3 \mathrm{mM}$ ) under normoxic conditions $\left(\mathrm{pO}_{2} 140 \mathrm{mmHg}\right.$ ) in a 3D representation with insulin concentration as height data and a surface color-coded for oxygen concentration (similar to Figure 10).

Additional file 3: Supporting Information, Video S2. Movie file showing the time-course of the insulin response of two islets to a glucose step ( $3 \mathrm{mM} \rightarrow 11 \mathrm{mM} \rightarrow 3 \mathrm{mM}$ ) under hypoxic conditions $\left(\mathrm{pO}_{2} 25 \mathrm{mmHg}\right)$ in a 3D representation with insulin concentration as height data and a surface color-coded for oxygen concentration (similar to Figure 10).

Acknowledgements

The financial support of the Diabetes Research Institute Foundation http://www.diabetesresearch.org that made this work possible is gratefully acknowledged.

Authors' contributions

$\mathrm{PB}$ is the only author.

\section{Competing interests}

The author declares that he has no competing interests.

Received: 25 April 2011 Accepted: 21 June 2011 Published: 21 June 2011

\section{References}

1. Hallgreen CE, Korsgaard TV, Hansen RN, Colding-Jørgensen M: The glucose-insulin control system. In Biosimulation in Drug Development. Edited by: Bertau M, Mosekilde E, Westerhoff HV. Weinheim: Wiley-VCH; 2008:141-196.

2. Suckale J, Solimena M: Pancreas islets in metabolic signaling-focus on the beta-cell. Front Biosci 2008, 13:7156-7171.

3. Buchwald P, Wang X, Khan A, Bernal A, Fraker C, Inverardi L, Ricordi C: Quantitative assessment of islet cell products: estimating the accuracy of the existing protocol and accounting for islet size distribution. Cell Transplant 2009, 18:1223-1235.

4. Kahn SE, Hull RL, Utzschneider KM: Mechanisms linking obesity to insulin resistance and type 2 diabetes. Nature 2006, 444:840-846.

5. Wyatt SB, Winters KP, Dubbert PM: Overweight and obesity: prevalence, consequences, and causes of a growing public health problem. Am J Med Sci 2006, 331:166-174.

6. Wang Y, Beydoun MA: The obesity epidemic in the United States-gender, age, socioeconomic, racial/ethnic, and geographic characteristics: a systematic review and meta-regression analysis. Epidemiol Rev 2007, 29:6-28.

7. Galletti PM, Colton CK, Jaffrin M, Reach G: Artificial pancreas. In The Biomedical Engineering Handbook Tissue Engineering and Artificial Organs.. 3 edition. Edited by: Bronzino JD. Boca Raton, FL: CRC Press; 2006:71.71-71.18.

8. Steil GM, Rebrin K, Janowski R, Darwin C, Saad MF: Modeling beta-cell insulin secretion-implications for closed-loop glucose homeostasis. Diabetes Technol Ther 2003, 5:953-964.

9. Steil GM, Panteleon AE, Rebrin K: Closed-loop insulin delivery-the path to physiological glucose control. Adv Drug Deliv Rev 2004, 56:125-144.

10. Hovorka R: Continuous glucose monitoring and closed-loop systems. Diabet Med 2006, 23:1-12.

11. Soon-Shiong P: Treatment of type I diabetes using encapsulated islets. Adv Drug Deliv Rev 1999, 35:259-270.

12. Silva Al, de Matos AN, Brons IG, Mateus M: An overview on the development of a bio-artificial pancreas as a treatment of insulin-dependent diabetes mellitus. Med Res Rev 2006, 26:181-222.

13. Teramura $\mathrm{Y}$, Iwata $\mathrm{H}$ : Bioartificial pancreas microencapsulation and conformal coating of islet of Langerhans. $\mathrm{Adv}$ Drug Deliv Rev 2010, 62:827-840.

14. Bergman RN, Ider YZ, Bowden CR, Cobelli C: Quantitative estimation of insulin sensitivity. Am J Physiol Endocrinol Metab 1979, 236:E667-E677.

15. Toffolo GM, Cobelli C: Insulin modeling. In Modeling Methodology for Physiology and Medicine. Edited by: Carson E, Cobelli C. San Diego: Academic Press; 2001:305-335.

16. Makroglou A, Li J, Kuang Y: Mathematical models and software tools for the glucose-insulin regulatory system and diabetes: an overview. Appl Num Math 2006, 56:559-573.

17. Boutayeb A, Chetouani A: A critical review of mathematical models and data used in diabetology. Biomed Eng Online 2006, 5:43, art

18. Matthews DR, Hosker JP, Rudenski AS, Naylor BA, Treacher DF, Turner RC: Homeostasis model assessment: insulin resistance and beta-cell function from fasting plasma glucose and insulin concentrations in man. Diabetologia 1985, 28:412-419. 
19. Wallace TM, Levy JC, Matthews DR: Use and abuse of HOMA modeling. Diabetes Care 2004, 27:1487-1495.

20. Reach $G$, Jaffrin MY: Kinetic modelling as a tool for the design of a vascular bioartificial pancreas: feedback between modelling and experimental validation. Comput Methods Programs Biomed 1990, 32:277-285.

21. Pillarella MR, Zydney AL: Theoretical analysis of the effect of convective flow on solute transport and insulin release in a hollow fiber bioartificial pancreas. J Biomech Eng 1990, 112:220-228.

22. Todisco S, Calabro V, lorio G: A lumped parameter mathematical model of a hollow fiber membrane device for the controlled insulin release. J Membr Sci 1995, 106:221-232.

23. Tziampazis E, Sambanis A: Tissue engineering of a bioartificial pancreas: modeling the cell environment and device function. Biotechnol Prog 1995, 11:115-126.

24. Buladi BM, Chang CC, Belovich JM, Gatica JE: Transport phenomena and kinetics in an extravascular bioartificial pancreas. AlChE J 1996, 42:2668-2682.

25. Dulong JL, Legallais C: Contributions of a finite element model for the geometric optimization of an implantable bioartificial pancreas. Artif Organs 2002, 26:583-589.

26. Dulong $\mathrm{J}$, Legallais $C$ : What are the relevant parameters for the geometrical optimization of an implantable bioartificial pancreas? J Biomech Eng 2005, 127:1054-1061.

27. Dionne KE, Colton CK, Yarmush ML: Effect of hypoxia on insulin secretion by isolated rat and canine islets of Langerhans. Diabetes 1993, 42:12-21.

28. Sweet IR, Khalil G, Wallen AR, Steedman M, Schenkman KA, Reems JA, Kahn SE, Callis JB: Continuous measurement of oxygen consumption by pancreatic islets. Diabetes Technol Therap 2002, 4:661-672.

29. Cabrera O, Jacques-Silva MC, Berman DM, Fachado A, Echeverri F, Poo RE, Khan A, Kenyon NS, Ricordi C, Berggren P-O, Caicedo A: Automated, high-throughput assays for evaluation of human pancreatic islet function. Cell Transplant 2008, 16:1039-1048.

30. Bocca N, Pileggi A, Molano RD, Marzorati S, Wu W, Bodor N, Ricordi C, Buchwald P: Soft corticosteroids for local immunosuppression: exploring the possibility for the use of loteprednol etabonate in islet transplantation. Pharmazie 2008, 63:226-232.

31. Dishinger JF, Reid KR, Kennedy RT: Quantitative monitoring of insulin secretion from single islets of Langerhans in parallel on a microfluidic chip. Anal Chem 2009, 81:3119-3127.

32. Truskey GA, Yuan F, Katz DF: Transport Phenomena in Biological Systems Upper Saddle River, NJ: Pearson Prentice Hall; 2004.

33. Buchwald P: FEM-based oxygen consumption and cell viability models for avascular pancreatic islets. Theor Biol Med Model 2009, 6:5.

34. Ohta M, Nelson D, Nelson J, Meglasson MD, Erecinska M: Oxygen and temperature dependence of stimulated insulin secretion in isolated rat islets of Langerhans. J Biol Chem 1990, 265:17525-17532.

35. Wang W, Upshaw L, Strong DM, Robertson RP, Reems J: Increased oxygen consumption rates in response to high glucose detected by a novel oxygen biosensor system in non-human primate and human islets. J Endocrinol 2005, 185:445-455.

36. Hedeskov CJ: Mechanism of glucose-induced insulin secretion. Physiol Rev 1980, 60:442-509.

37. Rorsman P, Eliasson L, Renstrom E, Gromada J, Barg S, Gopel S: The cell physiology of biphasic insulin secretion. News Physiol Sci 2000, 15:72-77.

38. Henquin JC: Triggering and amplifying pathways of regulation of insulin secretion by glucose. Diabetes 2000, 49:1751-1760.

39. Henquin JC: Regulation of insulin secretion: a matter of phase control and amplitude modulation. Diabetologia 2009, 52:739-751.

40. Henquin JC, Dufrane D, Nenquin M: Nutrient control of insulin secretion in isolated normal human islets. Diabetes 2006, 55:3470-3477.

41. Comsol AB: COMSOL Multiphysics Modeling Guide, version 3.4 COMSOL AB; 2007.

42. Riley KF, Hobson MP, Bence SJ: Mathematical Methods for Physics and Engineering. A Comprehensive Guide Cambridge: Cambridge University Press; 1997.

43. Groebe K, Erz S, Mueller-Klieser W: Glucose diffusion coefficients determined from concentration profiles in EMT6 tumor spheroids incubated in radioactively labeled L-glucose. Adv Exp Med Biol 1994, 361:619-625.

44. Bashkatov AN, Genina EA, Sinichkin YP, Kochubey VI, Lakodina NA, Tuchin W: Glucose and mannitol diffusion in human dura mater. Biophys J 2003, 85:3310-3318.

45. Kauri LM, Jung SK, Kennedy RT: Direct measurement of glucose gradients and mass transport within islets of Langerhans. Biochem Biophys Res Commun 2003, 304:371-377.

46. Novak MT, Yuan F, Reichert WM: Modeling the relative impact of capsular tissue effects on implanted glucose sensor time lag and signal attenuation. Anal Bioanal Chem 2010, 398:1695-1705

47. Søeborg T, Rasmussen CH, Mosekilde E, Colding-Jørgensen M: Absorption kinetics of insulin after subcutaneous administration. Eur J Pharm Sci 2009, 36:78-90.

48. Li RH, Altreuter DH, Gentile FT: Transport characterization of hydrogel matrices for cell encapsulation. Biotechnol Bioeng 1996, 50:365-373.

49. Hill AV: The possible effects of the aggregation of the molecules of haemoglobin on its dissociation curves. $J$ Physiol 1910, 40:iv-vii.

50. Hill AV: The combinations of haemoglobin with oxygen and with carbon monoxide. Biochem J 1913, 7:471-480.

51. Goutelle S, Maurin M, Rougier F, Barbaut X, Bourguignon L, Ducher M, Maire P: The Hill equation: a review of its capabilities in pharmacological modelling. Fundam Clin Pharmacol 2008, 22:633-648.

52. Michaelis L, Menten ML: Die Kinetik der Invertinwirkung. Biochem Z 1913, 49:333-369.

53. Buchwald P: Exploratory FEM-based multiphysics oxygen transport and cell viability models for isolated pancreatic islets. In Proceedings of the COMSOL Conference 2008 Boston. Edited by: Dravid V. Boston: Comsol, Inc.; 2008:

54. Wilson DF, Rumsey WL, Green TJ, Vanderkooi JM: The oxygen dependence of mitochondrial oxidative phosphorylation measured by a new optical method for measuring oxygen concentration. J Biol Chem 1988, 263:2712-2718 
55. Avgoustiniatos ES, Colton CK: Effect of external oxygen mass transfer resistances on viability of immunoisolated tissue. Ann NY Acad Sci 1997, 831:145-167.

56. Longo EA, Tornheim K, Deeney JT, Varnum BA, Tillotson D, Prentki M, Corkey BE: Oscillations in cytosolic free $\mathrm{Ca}^{2+}$ oxygen consumption, and insulin secretion in glucose-stimulated rat pancreatic islets. J Biol Chem 1991, 266:9314-9319.

57. Sweet IR, Gilbert M, Scott S, Todorov I, Jensen R, Nair I, Al-Abdullah I, Rawson J, Kandeel F, Ferreri K: Glucosestimulated increment in oxygen consumption rate as a standardized test of human islet quality. Am J Transplant 2008, 8:183-192.

58. Cornolti R, Figliuzzi M, Remuzzi A: Effect of micro-and macroencapsulation on oxygen consumption by pancreatic islets. Cell Transplant 2009, 18:195-201.

59. Hedeskov CJ, Hertz L, Nissen C: The effect of mannoheptulose on glucose-and pyruvate-stimulated oxygen uptake in normal mouse pancreatic islets. Biochim Biophys Acta 1972, 261:388-397.

60. Goto M, Abe H, Ito-Sasaki T, Goto M, Inagaki A, Ogawa N, Fujimori K, Kurokawa Y, Matsue T, Satomi S: A novel predictive method for assessing the quality of isolated pancreatic islets using scanning electrochemical microscopy. Transplant Proc 2009, 41:311-313.

61. Comsol AB: COMSOL Multiphysics User's Guide, version 3.4 COMSOL AB; 2007.

62. Martin $Y$, Vermette P: Bioreactors for tissue mass culture: design, characterization, and recent advances. Biomaterials 2005, 26:7481-7503

63. Grodsky GM: A threshold distribution hypothesis for packet storage of insulin and its mathematical modeling. J Clin Invest 1972, 51:2047-2059.

64. Purrello F, Rabuazzo AM, Anello M, Patane G: Effects of prolonged glucose stimulation on pancreatic beta cells: from increased sensitivity to desensitization. Acta Diabetol Lat 1996, 33:253-256.

65. Pedersen MG, Corradin A, Toffolo GM, Cobelli C: A subcellular model of glucose-stimulated pancreatic insulin secretion. Philos Transact A Math Phys Eng Sci 2008, 366:3525-3543.

66. Pedersen MG, Toffolo GM, Cobelli C: Cellular modeling: insight into oral minimal models of insulin secretion. Am J Physiol Endocrinol Metab 2010, 298:E597-E601.

67. Topp B, Promislow K, deVries G, Miura RM, Finegood DT: A model of beta-cell mass, insulin, and glucose kinetics: pathways to diabetes. J Theor Biol 2000, 206:605-619.

68. Malaisse WJ, Sener A, Herchuelz A, Hutton JC: Insulin release: the fuel hypothesis. Metabolism 1979, 28:373-386

69. Matschinsky FM, Glaser B, Magnuson MA: Pancreatic beta-cell glucokinase: closing the gap between theoretical concepts and experimental realities. Diabetes 1998, 47:307-315.

70. Fridlyand LE, Philipson LH: Glucose sensing in the pancreatic beta cell: a computational systems analysis. Theor Biol Med Model 2010, 7:15.

71. Ritzel RA, Veldhuis JD, Butler PC: Glucose stimulates pulsatile insulin secretion from human pancreatic islets by increasing secretory burst mass: dose-response relationships. J Clin Endocrinol Metab 2003, 88:742-747.

72. Nomura M, Shichiri M, Kawamori R, Yamasaki Y, Iwama N, Abe H: A mathematical insulin-secretion model and its validation in isolated rat pancreatic islets perifusion. Comput Biomed Res 1984, 17:570-579.

73. Breda E, Cavaghan MK, Toffolo G, Polonsky KS, Cobelli C: Oral glucose tolerance test minimal model indexes of betacell function and insulin sensitivity. Diabetes 2001, 50:150-158.

74. Mari A, Schmitz O, Gastaldelli A, Oestergaard T, Nyholm B, Ferrannini E: Meal and oral glucose tests for assessment of beta-cell function: modeling analysis in normal subjects. Am J Physiol Endocrinol Metab 2002, 283:E1159-E1 166.

75. Avgoustiniatos ES: Oxygen diffusion limitations in pancreatic islet culture and immunoisolation. PhD Thesis MIT; 2001.

76. Johnson AS, Fisher RJ, Weir GC, Colton CK: Oxygen consumption and diffusion in assemblages of respiring spheres: Performance enhancement of a bioartificial pancreas. Chem Eng Sci 2009, 64:4470-4487.

77. Buchwald P: A general bilinear model to describe growth or decline time-profiles. Math Biosci 2007, 205:108-136

78. Dufrane $\mathrm{D}$, Nenquin M, Henquin JC: Nutrient control of insulin secretion in perifused adult pig islets. Diabetes Metab 2007, 33:430-438

79. Buchwald P: COMSOL Multiphysics-based exploratory insulin secretion model for isolated pancreatic islets. Presented at COMSOL Conference 2010 Boston. COMSOL Conference 2010 Boston; October 7-9; Boston, MA COMSOL, Inc.; 2010.

80. Henquin $J C$, Nenquin $M$, Stiernet $P$, Ahren B: In vivo and in vitro glucose-induced biphasic insulin secretion in the mouse: pattern and role of cytoplasmic Ca2+ and amplification signals in beta-cells. Diabetes 2006, 55:441-451.

81. Ricordi C, Gray DWR, Hering BJ, Kaufman DB, Warnock GL, Kneteman NM, Lake SP, London NJM, Socci C, Alejandro R, Zeng Y, Scharp DW, Viviani G, Falqui L, Tzakis A, Bretzel RG, Federlin K, Pozza G, James RFL, Rajotte RV, Di Carlo V, Morris PJ, Sutherland DER, Starzl TE, Mintz DH, Lacy PE: Islet isolation assessment in man and large animals. Acta Diabetol Lat 1990, 27:185-195.

82. Kissler HJ, Niland JC, Olack B, Ricordi C, Hering BJ, Naji A, Kandeel F, Oberholzer J, Fernandez L, Contreras J, Stiller T, Sowinski J, Kaufman DB: Validation of methodologies for quantifying isolated human islets: an islet cell resources study. Clin Transplant 2010, 24:236-242.

83. Baum D, Griepp R, Porte D Jr: Glucose-induced insulin release during acute and chronic hypoxia. Am J Physiol 1979, 237:E45-E50

84. Carlsson PO, Palm F, Andersson A, Liss P: Chronically decreased oxygen tension in rat pancreatic islets transplanted under the kidney capsule. Transplantation 2000, 69:761-766.

85. MacGregor RR, Williams SJ, Tong PY, Kover K, Moore WW, Stehno-Bittel L: Small rat islets are superior to large islets in in vitro function and in transplantation outcomes. Am J Physiol Endocrinol Metab 2006, 290:E771-E779.

86. Lehmann R, Zuellig RA, Kugelmeier P, Baenninger PB, Moritz W, Perren A, Clavien PA, Weber M, Spinas GA: Superiority of small islets in human islet transplantation. Diabetes 2007, 56:594-603.

87. O'Sullivan ES, Johnson AS, Omer A, Hollister-Lock J, Bonner-Weir S, Colton CK, Weir GC: Rat islet cell aggregates are superior to islets for transplantation in microcapsules. Diabetologia 2010, 53:937-945.

88. Skiles ML, Fancy R, Topiwala P, Sahai S, Blanchette JO: Correlating hypoxia with insulin secretion using a fluorescent hypoxia detection system. J Biomed Mater Res B Appl Biomater 2011, 97B:148-155. 
89. Ricordi C, Strom TB: Clinical islet transplantation: advances and immunological challenges. Nat Rev Immunol 2004, 4:259-268.

90. Fiorina P, Shapiro AM, Ricordi C, Secchi A: The clinical impact of islet transplantation. Am J Transplant 2008, 8:1990-1997.

91. King S: The evolution of islet encapsulation ventures [http://www.solvingdiabetes.org/2009/05/21/history-of-diabetesresearch].

92. Garfinkel MR, Harland RC, Opara EC: Optimization of the microencapsulated islet for transplantation. J Surg Res 1998, 76:7-10.

93. de Vos P, Smedema I, van Goor H, Moes H, van Zanten J, Netters S, de Leij LF, de Haan A, de Haan BJ: Association between macrophage activation and function of micro-encapsulated rat islets. Diabetologia 2003, 46:666-673.

94. Fort A, Fort N, Ricordi C, Stabler CL: Biohybrid devices and encapsulation technologies for engineering a bioartificial pancreas. Cell Transplant 2008, 17:997-1003.

95. Buchwald P, Bocca N, Marzorati S, Hochhaus G, Bodor N, Stabler C, Kenyon NS, Inverardi L, Molano RD, Ricordi C, Pileggi A: Feasibility of localized immunosuppression: 1. Exploratory studies with glucocorticoids in a biohybrid device designed for cell transplantation. Pharmazie 2010, 65:421-428.

96. Rorsman P, Renström E: Insulin granule dynamics in pancreatic beta cells. Diabetologia 2003, 46:1029-1045

97. MacDonald PE, Joseph JW, Rorsman P: Glucose-sensing mechanisms in pancreatic beta-cells. Philos Trans $R$ Soc Lond B Biol Sci 2005, 360:2211-2225.

98. Nesher R, Cerasi E: Modeling phasic insulin release: immediate and time-dependent effects of glucose. Diabetes 2002, 51(Suppl 1):S53-S59.

99. Renard E, Place J, Cantwell M, Chevassus H, Palerm CC: Closed-loop insulin delivery using a subcutaneous glucose sensor and intraperitoneal insulin delivery: feasibility study testing a new model for the artificial pancreas. Diabetes Care 2010, 33:121-127.

100. Cretti A, Lehtovirta M, Bonora E, Brunato B, Zenti MG, Tosi F, Caputo M, Caruso B, Groop LC, Muggeo M, Bonadonna RC: Assessment of beta-cell function during the oral glucose tolerance test by a minimal model of insulin secretion. Eur J Clin Invest 2001, 31:405-416.

doi:10.1186/1742-4682-8-20

Cite this article as: Buchwald: A local glucose-and oxygen concentration-based insulin secretion model for pancreatic islets. Theoretical Biology and Medical Modelling 2011 8:20.

\section{Submit your next manuscript to BioMed Central} and take full advantage of:

- Convenient online submission

- Thorough peer review

- No space constraints or color figure charges

- Immediate publication on acceptance

- Inclusion in PubMed, CAS, Scopus and Google Scholar

- Research which is freely available for redistribution 